\title{
Economies of Scale, Technical Change and Persistent and Time-Varying Cost Efficiency in Indian Banking: Do Ownership, Regulation and Heterogeneity Matter?
}

\author{
Oleg Badunenko* $\quad$ Subal C. Kumbhakar ${ }^{\dagger}$
}

\begin{abstract}
Banks with different ownership types adjust differently to changes in regulatory environments. Although this topic has been widely studied, all the previous studies fail to control for bank-heterogeneity (bank-specific effects) in e stimating c ost structure and efficiency. We propose a model where we control for bank-heterogeneity, and introduce persistent and time-varying inefficiency. Additionally we incorporate determinants of both persistent and time-varying inefficiency as well as production risks. Furthermore, our model allows estimation of different technologies for different ownership types jointly. We use this model to analyze the effect of regulation in Indian banking. We find t hat $\mathrm{p}$ rivate $\mathrm{b}$ anks $\mathrm{h}$ ave $\mathrm{n}$ ot $\mathrm{e}$ xhausted $\mathrm{t}$ heir e conomies of scale, foreign banks are operating under diseconomies of scale, especially after the reforms, and scale economies of state owned banks are unaffected by regulation. Banks of all ownership types have enjoyed technical progress; however, foreign banks have benefited the most, followed by state owned banks. Only state banks were able to improve their cost efficiency, while private banks, and especially foreign banks, were lagging behind their cost frontiers.
\end{abstract}

JEL: G18, G21, C15, C23

Keywords: Finance, Persistent and time-varying inefficiency; Production risk; Private, Public and Foreign; Regulation

\footnotetext{
*Corresponding author, Oleg Badunenko, Economics and Finance Group, Portsmouth Business School, University of Portsmouth, Portsmouth, United Kingdom. Phone: +44 23928448 31, E-mail: oleg.badunenko@port.ac.uk.

${ }^{\dagger}$ Subal C. Kumbhakar, Department of Economics, State University of New York, Binghamton, NY 139026000, USA and University of Stavanger Business School, Norway. Phone: 607-777-4762, Fax: 607-777-2681, E-mail: kkar@binghamton.edu.
} 


\section{Introduction}

There is an extensive literature on the effect of different types of regulation on performance of financial institutions. Deregulation of the banking industry is perhaps studied the most. One of the reasons behind banking deregulation all over the world is the belief that deregulation increases competition, and higher competition tends to force banks to use resources efficiently leading to higher productivity. Consequently, this is the subject of study of many papers across many different countries (e.g., Fu and Heffernan 2009). Part of the reason for the intense scrutiny of the banking sector is that banks (and financial institutions in general) control finances - the main driver of economic growth and stability. On the other hand, when there are dangers of 'overheating' and signs of excessive risk taking, authorities increase the 'amount' of regulation with an attempt to achieve greater financial stability (e.g., Doumpos et al. 2015). With regulations, banks and/or financial institutions may not feel the pressure and incentive to operate efficiently. This is often referred to as the 'quiet life' hypothesis (Hicks 1935), meaning that firms tend to operate inefficiently when the markets are non-competitive. However, empirical results do not always support this premise (Casu and Girardone 2009, Berger, Klapper and Turk-Ariss 2009, Fu and Heffernan 2009). According to the 'competition-fragility' hypothesis, greater competition erodes market power, lowers interest margins, reduces the franchise value of banks and increases the loan portfolio as measured by increased non-performing loans. In contrast, the 'competition-stability' hypothesis states that the risk-incentive mechanism operates in the opposite direction, causing banks to become more risky as their markets become more non-competitive (Boyd and De Nicoló 2005). Additionally, banks operating in the non-competitive market are likely to take more risks if they work under the protection of government regulations. Further, higher risk taking could also be associated with reductions in efficiency (Fiordelisi et al. 2011). Thus it is not clear whether increases in competition will always improve efficiency and productivity. Sometimes it takes time for banks to adjust to deregulatory changes and banks of different ownership types may react differently with different speeds of adjustment. This means efficiency and productivity improvements, if any, may not be instantaneous.

There are many studies that focus on the effects of banking deregulation on efficiency and productivity growth. What is unique about the banking industry in India is that there are three distinct ownership types. That is, state-owned, privately-owned and foreign-owned banks simultaneously operate in the Indian banking industry. Deregulation, whatever form it takes, is likely to affect banks of different ownership type differently. Different ownerships react with different speeds to the change of regulatory environment (Isik and Hassan 2002, 
Leightner and Lovell 1998) and perform differently (e.g., Berger, Hasan and Zhou 2009). This gives us an opportunity to examine whether one ownership type outperforms another in terms of improvement in productivity and efficiency after deregulation. For example, the early efficiency study of Bhattacharyya et al. (1997) focused on the relative performance of commercial banks under three different kinds of ownership (private, public, and foreign), but the coverage was limited to only a few years after deregulation. In the post reform period, a number of studies have analyzed the impact of deregulation on the efficiency of Indian banks (Kumbhakar and Sarkar 2003, 2005, Das and Ghosh 2006, Ray and Das 2010, Das and Kumbhakar 2012). The broad finding emanating from these studies was that state-owned banks (SOBs) performed better than private sector banks, and medium sized state-owned are more likely to operate at higher levels of efficiency and have, on an average, less non-performing loans (Casu et al. 2013, Das and Kumbhakar 2012, Kumbhakar and Sarkar 2003).

What is missing in all these studies is the failure to control for systematic differences among banks in estimating productivity with or without efficiency. The exceptions are Restrepo-Tobón et al. (2015) and Malikov et al. (2014) who examined TFP of US commercial banks and credit unions. They control for bank-specific effects but did not consider inefficiency. That is, they assumed that all the banks are fully efficient in every year. Bank inefficiency estimates typically reflect on managerial skill, which lead to deviations from the assumed operating behavior. These deviations, however, may arise due to the failure to account for bank-heterogeneity. Additionally, the inefficiency of banks in a panel study is either assumed to be time-invariant or time-varying. Time-invariant bank inefficiency captures persistent inefficiency attributed to structural rigidities, regulatory constraints where it is reasonable to assume that the these factors remain constant over time especially in a short panel. Time-varying or time-varying inefficiency, in contrast, captures the temporal pattern of inefficiency that is examined to capture catch-up (the rate in which inefficient banks move to the frontier). Banking studies up until now estimated either persistent or time-varying inefficiency but not both. It is likely that, in reality, one part of inefficiency is persistent while another part is time-varying. Further, there might be factors that can explain differences in them across banks and over time.

Recently Kumbhakar et al. (2014), Colombi et al. (2014) and Tsionas and Kumbhakar (2014) introduced a four-component stochastic frontier model which not only allows to control for random bank-specific effects, but also disentangles persistent inefficiency from 
time-varying inefficiency. ${ }^{1}$ In this paper, we propose a model where all the four components are assumed to be heteroscedastic. The heteroscedasticities associated with the persistent and time-varying inefficiency components are viewed as determinants of persistent and timevarying inefficiency. Similarly, heteroscedasticy of the bank-effects and the noise term are interpreted as persistent and long-run production risk. Here we are using the argument advanced by production economists, mainly in agriculture, in interpreting the variance of production shocks as risk which can be explained by some observed phenomena. Furthermore, we allow the technology for each ownership type to be different, and devised a procedure to estimate them all together instead of estimating them separately for each ownership type (e.g., Altunbas et al. 2001, Casu et al. 2013). This is the most general panel data stochastic frontier model which we label as the heteroscedastic four-component model. Our main focus in this paper is on this new model.

Since our heteroscedastic model can generate many special cases that are widely used in the literature, first we present estimates of returns to scale (RTS), technical change, and persistent and time-varying efficiency from our heteroscedastic four-component model. We also present results from two other misspecified models to show the effect of failure to include one or more of the components, in particular, (i) the widely used model with only time-varying inefficiency (with determinants) and noise; and (ii) the recently developed homoscedastic four-component model. Our goal is to enrich the existing literature by analyzing the effect of banking regulation on the RTS, technical change and efficiency of foreign, private and state Indian banks using our new model.

The rest of the paper is organized as follows. Section 2 presents the heteroscedastic fourcomponent stochastic frontier panel data model followed by the empirical model specification and a brief overview of the Indian banking data in Section 3. The empirical results (viz., the impact of regulatory change on RTS, technical change and efficiency) are discussed in Section 4 and Section 5 concludes the paper.

\section{Methodology}

In this section, we describe the production technology in general in terms of the dual cost function with input-oriented technical inefficiency. Following the banking literature we use

1 Filippini and Greene (2016) proposed a simulated maximum likelihood method to estimate this homoscedastic four-component model. 
a cost minimizing framework to model the underlying banking technology. In a panel data model which is used in most of the papers, the cost function is specified as

$$
\log c_{i t}=h\left(\boldsymbol{y}_{i t}, \boldsymbol{w}_{i t} ; \boldsymbol{\theta}\right)+v_{i t}+u_{i t}
$$

where $i=1, \cdots, n$ denotes the $i$ th bank and $t=1, \cdots, T_{i}$ denotes the time period in which bank $i$ is observed, $c_{i t}$ measures the total costs, $\boldsymbol{y}_{i t}$ denotes the vector of outputs, $\boldsymbol{w}_{i t}$ denotes the vector of input prices of bank $i$ in time period $t$, and $h(\cdot)$ is the cost function that represents the (dual) banking technology. Finally, $v_{i t}$ is the noise term and $u_{i t} \geq 0$ is time-varying technical inefficiency. See Kumbhakar et al. (2015) for a detailed discussion of various models with different specifications of the time-varying inefficiency term, $u_{i t}$.

Although panel data are extensively used in the literature, only a few papers use models that make use of the panel nature of the data by including bank heterogeneity. Kumbhakar (1991), Kumbhakar and Heshmati (1995) and Kumbhakar and Hjalmarsson (1993, 1995) introduced heterogeneity but they interpreted it as persistent inefficiency, viz.,

$$
\log c_{i t}=c\left(\boldsymbol{y}_{i t}, \boldsymbol{w}_{i t} ; \boldsymbol{\theta}\right)+u_{0 i}+v_{i t}+u_{i t},
$$

where $u_{0 i}$ is assumed to be persistent inefficiency not firm heterogeneity. Greene (2005) used the same specification but interpreted the time-invariant term $u_{0 i}$ as firm-effects instead of persistent inefficiency. Since the time-invariant component can include both firm effects (heterogeneity) Colombi et al. (2014), Kumbhakar et al. (2014) and Tsionas and Kumbhakar (2014) introduced a model that split the error term into four components. The first component captures firms' latent heterogeneity (see Greene 2005) and the second component captures log-run/persistent/time-invariant inefficiency as in Kumbhakar and Hjalmarsson (1993), Kumbhakar and Heshmati (1995) and Kumbhakar and Hjalmarsson (1995), both of which are time-invariant. The third component captures time-varying inefficiency (see Kumbhakar 1987), while the last component captures random shocks. Both the third and fourth components are observation-specific (i.e., vary across firms and over time). Thus the model is formally expressed as

$$
\log c_{i t}=h\left(\boldsymbol{y}_{i t}, \boldsymbol{w}_{i t} ; \boldsymbol{\theta}\right)+v_{0 i}+u_{0 i}+v_{i t}+u_{i t},
$$

where $u_{0 i} \geq 0$ and $u_{i t} \geq 0$ represent persistent and time-varying inefficiency, respectively, while $v_{0 i}$ captures latent firm heterogeneity and $v_{i t}$ is the classical random noise. We call this homoscedastic four-component model. The four-component homoscedastic model has 
been applied to analyze the efficiency in health care, agriculture, transportation (Colombi et al. 2014, Kumbhakar et al. 2014) and US banks (Tsionas and Kumbhakar 2014). Kumbhakar and Lai (2016) further extended the model by considering a system of revenue share equations each having four-components.

In the homoscedastic four-component model, all the components are independently and identically distributed (i.i.d.) random variables. Thus the model can not be useful for policy purposes unless efficiency levels can be systematically changed by changing the policy variables. In other words, we need a model in which inefficiency is systematically related to some policy variables and firm characteristics. For example, if the regulators want the firms they regulate to move faster to the frontier (increase the catch-up rate) by giving them incentives (carrots), the time-varying inefficiency has to be related to some policy variables that the regulators can change. Similarly, to talk about reducing production risk, the model has to allow the variances of the time-invariant firm-effects and the noise term to depend on some factors. In summary, although the homoscedastic four-component model can give us estimates of persistent and time-varying efficiency, the model cannot explain the determinants of inefficiency, and therefore, cannot be used for prescribing policies to increase efficiency. Similarly, the model cannot explain differences within and between production risks.

\subsection{Heterogeneity in inefficiency and production risk}

Since our application focuses on the role of regulation and regulatory variables as well as ownership in efficiency, we argue that both the regulator and firms are interested in knowing what determines persistent and time-varying inefficiency, and what their marginal effects are. For example, the regulator might be more interested in the drivers of persistent inefficiency, while firms presumably strive to eliminate the long-run inefficiency.

In our specification we use the determinants of persistent inefficiency to appear in the (pre-truncated) variance of $u_{0 i}$ which is time-invariant, viz.,

$$
u_{0 i} \sim N^{+}\left(0, \sigma_{u 0 i}^{2}\right) \text { where } \sigma_{u 0 i}^{2}=\sigma_{u 0}^{2} \exp \left(\boldsymbol{z}_{u 0 i} \boldsymbol{\gamma}_{u 0}\right), \quad i=1, \cdots, n
$$

and $\boldsymbol{z}_{u 0 i}$ is the vector of covariates that determines the heteroscedasticity function of persistent inefficiency and is by definition time-invariant. Since $E\left(u_{0 i}\right)=\sqrt{(2 / \pi)} \sigma_{u 0 i}=$ $\sqrt{(2 / \pi)} \exp \left(\frac{1}{2} \boldsymbol{z}_{u 0 i} \gamma_{u 0}\right)$, the $\boldsymbol{z}_{u 0 i}$ variables can be viewed as determinants of persistent inef- 
ficiency. ${ }^{2}$ Variables in $\boldsymbol{z}_{u 0 i}$ may vary by firms, but not over time within firms. This means that $\sigma_{u 0 i}^{2}$ is explained only by time-invariant covariates.

In a similar fashion, we introduce determinants of time-varying inefficiency via the pretruncated variance of $u_{i t}$. More specifically, we assume

$$
u_{i t} \sim N^{+}\left(0, \sigma_{u i t}^{2}\right) \text { where } \sigma_{u i t}^{2}=\sigma_{u}^{2} \exp \left(\boldsymbol{z}_{u i t} \boldsymbol{\gamma}_{u}\right), \quad i=1, \cdots, n, \quad t=1, \cdots, T_{i}
$$

where $\boldsymbol{z}_{\text {uit }}$ denotes the vector of covariates that explains time-varying inefficiency. Since $u_{i t}$ is half-normal, $E\left(u_{i t}\right)=\sqrt{(2 / \pi)} \sigma_{\text {uit }}=\sqrt{(2 / \pi)} \exp \left(\frac{1}{2} \boldsymbol{z}_{\text {uit }} \boldsymbol{\gamma}_{u}\right)$, and therefore, anything that affects $\sigma_{\text {uit }}$ also affects time-varying inefficiency. As noted before, time-varying inefficiency can also be modeled assuming the pre-truncation mean of $u_{i t}$ to be a function of the $z_{u i t}$ variables.

One can further extend the model to accommodate heteroscedasticity associated with both firm-effects and the noise terms, which can be viewed as production risk. Although we are viewing $v_{0 i}$ as random firm effects, one can view its variance (the time-invariant component) as a production risk which is firm-specific. ${ }^{3}$ Similarly, the variance of the firmspecific and time-varying shocks $\left(v_{i t}\right)$ can be interpreted as production risk that is both firmand time-specific. We specify them as

$$
\begin{aligned}
v_{0 i} & \sim N\left(0, \sigma_{v 0 i}^{2}\right) \text { where } \sigma_{v 0 i}^{2}=\sigma_{v 0}^{2} \exp \left(\boldsymbol{z}_{v 0 i} \boldsymbol{\gamma}_{v 0}\right), \quad i=1, \cdots, n, \\
v_{i t} & \sim N\left(0, \sigma_{v i t}^{2}\right) \text { where } \sigma_{v i t}^{2}=\sigma_{v}^{2} \exp \left(\boldsymbol{z}_{v i t} \boldsymbol{\gamma}_{v}\right), \quad i=1, \cdots, n, \quad t=1, \cdots, T_{i},
\end{aligned}
$$

where $\boldsymbol{z}_{v 0 i}$ denotes the vector of time-invariant covariates that determines persistent production risk (variance of random firm-effects). Similarly, $\boldsymbol{z}_{\text {vit }}$ denotes the vector of covariates that determines time-varying production risk (variance of both the firm-specific and timevarying random noise).

\section{$2.2 \quad$ Flexible technology}

Our sample contains banks with foreign $(F)$, private $(P)$, and state $(S)$ ownerships. If they all share a common technology, the parameters in (3), as well as in (4), (5), (6), and (7)

2 Persistent inefficiency can also be modeled assuming the pre-truncation mean of $u_{0 i}$ to be a function of the $z_{u 0}$ variables.

3 See Just and Pope (1978) and the many papers that followed their lead in agricultural economics for this. 
will be the same for all banks. Banks of different ownership, however, might have different technologies, i.e., have different cost frontiers (see Altunbas et al. 2001). One option is to estimate each technology separately using data for each ownership type, assuming that there are enough data for each group. The other option is to estimate all three technologies together by combining them in a single model (Triebs et al. 2016), viz.,

$$
\log c_{i t}=D_{F} \cdot \log c_{i t}^{F}+D_{P} \cdot \log c_{i t}^{P}+D_{S} \cdot \log c_{i t}^{S}
$$

where $D_{F}, D_{P}$ and $D_{S}$ are dummy variables corresponding to foreign, private and state ownership, respectively. ${ }^{4}$ Furthermore,

$$
\begin{aligned}
& \log c_{i t}^{F}=h^{F}\left(\boldsymbol{y}_{i t}^{F}, \boldsymbol{w}_{i t}^{F} ; \boldsymbol{\theta}^{F}\right)+v_{0 i}^{F}+u_{0 i}^{F}+v_{i t}^{F}+u_{i t}^{F} \\
& \log c_{i t}^{P}=h^{P}\left(\boldsymbol{y}_{i t}^{P}, \boldsymbol{w}_{i t}^{P} ; \boldsymbol{\theta}^{P}\right)+v_{0 i}^{P}+u_{0 i}^{P}+v_{i t}^{P}+u_{i t}^{P} \\
& \log c_{i t}^{S}=h^{S}\left(\boldsymbol{y}_{i t}^{S}, \boldsymbol{w}_{i t}^{S} ; \boldsymbol{\theta}^{S}\right)+v_{0 i}^{S}+u_{0 i}^{S}+v_{i t}^{S}+u_{i t}^{S},
\end{aligned}
$$

where $\gamma_{v}, \gamma_{u}, \gamma_{v 0}$, and $\gamma_{u 0}$ in (7), (5), (4), and (6) are ownership-specific. Note that the technologies in (9)-(11) are ownership-specific. Using the ownership dummy variables we combine (9)-(11) in (8) and estimate all the parameters jointly. By doing this, one can test hypotheses relating to technologies across different ownerships. In estimating (8) we are assuming the error components to be independent across ownership types. We leave relaxing this assumption for the future.

Specification (8) is flexible because it allows banks of different types to operate at their own frontier. Further, econometrically, it allows one to test whether banks have a common technology by performing a likelihood ratio test.

The model in (8) along with (4), (5), (6) and (7) gives us the most flexible specification of the stochastic frontier model to date. Depending on the application and availability of information on the different sets of $z$ variables, researchers can choose which extensions to use. The model also allows the users to test hypotheses related to these extensions/generalizations.

4 Although the number of parameters are the same under both options, the degrees of freedom will be higher under the second option because it uses the full sample. 


\subsection{Full maximum likelihood method}

Rewrite model (3) as

$$
\log c_{i t}=h\left(\boldsymbol{y}_{i t}, \boldsymbol{w}_{i t} ; \boldsymbol{\theta}\right)+\epsilon_{0 i}+\epsilon_{i t}
$$

where $\epsilon_{i t}=v_{i t}+u_{i t}$ and $\epsilon_{0 i}=v_{0 i}+u_{0 i}$ decompose the error term into two 'composed error' terms (both of which contain inefficiency and noise terms). This decomposition will be useful later when we discuss the estimation of the model.

To obtain a tractable likelihood function, we follow Colombi et al. (2014) and draw results from skew normal and closed skew normal (CSN) distributions. Assuming $v_{i t}$ is an independent [in probability] random normal variable and $u_{i t}$ is an independent random half normal variable, $\epsilon_{i t}$ in (12) has a skew normal distribution. Using the same argument, $\epsilon_{0 i}$ in (12) has a skew normal distribution when $v_{0 i}$ is an independent random normal variable and $u_{0 i}$ is an independent random half normal variable. Thus, the composed error term $\epsilon_{0 i}+\epsilon_{i t}$ in (12) has a CSN distribution (being the sum of two independent skew normal distributions), which has a well defined pdf that is used to define the log-likelihood function, the maximization of which gives the MLE of all the parameters.

The model in (12) can be rewritten in a compact form, viz.,

$$
\log \boldsymbol{c}_{i}=h\left(\boldsymbol{y}_{i}, \boldsymbol{w}_{i} ; \boldsymbol{\theta}\right)+\mathbf{1}_{T_{i}} v_{0 i}+\boldsymbol{A} \boldsymbol{u}_{i}+\boldsymbol{v}_{i}, \quad \forall i
$$

where bold symbols denote vectors for bank $i, \boldsymbol{u}_{i}=\left(u_{0 i}, u_{i 1}, \ldots, u_{i T_{i}}\right)^{\prime}, \boldsymbol{v}_{i}=\left(v_{i 1}, \ldots, v_{i T_{i}}\right)^{\prime}$, $\boldsymbol{A}=\left[\mathbf{1}_{T_{i}} \boldsymbol{I}_{T_{i}}\right], \mathbf{1}_{T_{i}}$ is the column vector of length $T_{i}$ and $\boldsymbol{I}_{T_{i}}$ is the identity matrix of dimension $T_{i}$. Since the composed error term $\boldsymbol{\epsilon}_{i}=\mathbf{1}_{T_{i}} v_{0 i}+\boldsymbol{A} \boldsymbol{u}_{i}+\boldsymbol{v}_{i}$ follows a CSN distribution, its joint density can be derived from the definition of a CSN probability density function, and the resulting panel level log-likelihood function of the four component model is given by:

$$
\begin{aligned}
\log L_{i}\left(\boldsymbol{\theta}, \boldsymbol{\gamma}_{u 0}, \boldsymbol{\gamma}_{v 0}, \boldsymbol{\gamma}_{u}, \boldsymbol{\gamma}_{v}\right) & =\left(T_{i}+1\right) \log 2+\log \phi_{T_{i}}\left(\boldsymbol{r}_{i}, \mathbf{0}, \boldsymbol{\Sigma}_{i}+\boldsymbol{A} \boldsymbol{V}_{i} \boldsymbol{A}^{\prime}\right) \\
& +\log \bar{\Phi}_{T_{i}+1}\left(\boldsymbol{R}_{i} \boldsymbol{r}_{i}, \boldsymbol{\Lambda}_{i}\right)
\end{aligned}
$$

where $\boldsymbol{r}_{i}=\log \boldsymbol{c}_{i}-h\left(\boldsymbol{y}_{i}, \boldsymbol{w}_{i} ; \boldsymbol{\theta}\right)$, the diagonal elements of $\boldsymbol{V}_{i}$ are $\left[\exp \left(\boldsymbol{z}_{u 0 i} \boldsymbol{\gamma}_{u 0}\right) \exp \left(\boldsymbol{z}_{u i t} \boldsymbol{\gamma}_{u}\right)\right]$, $\boldsymbol{\Sigma}_{i}=\exp \left(\boldsymbol{z}_{v i t} \boldsymbol{\gamma}_{v}\right) \boldsymbol{I}_{T_{i}}+\exp \left(\boldsymbol{z}_{v 0 i} \boldsymbol{\gamma}_{v 0}\right) \mathbf{1}_{T_{i}} \mathbf{1}_{T_{i}}^{\prime},{ }^{5} \boldsymbol{\Lambda}_{i}=\boldsymbol{V}_{i}-\boldsymbol{V}_{i} \boldsymbol{A}^{\prime}\left(\boldsymbol{\Sigma}_{i}+\boldsymbol{A} \boldsymbol{V}_{i} \boldsymbol{A}^{\prime}\right)^{-1} \boldsymbol{A} \boldsymbol{V}_{i}=$ $\left(\boldsymbol{V}_{i}^{-1}+\boldsymbol{A}^{\prime} \boldsymbol{\Sigma}_{i}^{-1} \boldsymbol{A}\right)^{-1}, \boldsymbol{R}_{i}=\boldsymbol{V}_{i} \boldsymbol{A}^{\prime}\left(\boldsymbol{\Sigma}_{i}+\boldsymbol{A} \boldsymbol{V}_{i} \boldsymbol{A}^{\prime}\right)^{-1}=\boldsymbol{\Lambda}_{i} \boldsymbol{A}^{\prime} \boldsymbol{\Sigma}_{i}^{-1}, \phi_{q}(x, \boldsymbol{\mu}, \boldsymbol{\Omega})$ is the den-

5 Note that $\exp \left(\boldsymbol{z}_{u 0 i} \boldsymbol{\gamma}_{u 0}\right)$ and $\exp \left(\boldsymbol{z}_{v 0 i} \boldsymbol{\gamma}_{v 0}\right)$ are both scalars, whereas $\exp \left(\boldsymbol{z}_{u i t} \boldsymbol{\gamma}_{u}\right)$ and $\exp \left(\boldsymbol{z}_{v i t} \boldsymbol{\gamma}_{v}\right)$ are both vectors of length $T_{i}$. Changing the notation of (4), (5), (6), and (7), $\gamma_{u 0}, \gamma_{v 0}, \gamma_{u}$, and $\gamma_{v}$ include 
sity function of a $q$-dimensional normal variable with expected value $\boldsymbol{\mu}$ and variance $\boldsymbol{\Omega}$ and $\bar{\Phi}_{q}(\boldsymbol{\mu}, \boldsymbol{\Omega})$ is the probability that a $q$-variate normal variable of expected value $\boldsymbol{\mu}$ and variance $\Omega$ belongs to the positive orthant.

\subsection{A simulated maximum likelihood estimator}

Although the CSN framework gives a closed form expression of the log-likelihood function, implementing it in practice is a daunting task. Using the insights of Butler and Moffitt (1982), Filippini and Greene (2016) note that the density can be greatly simplified by conditioning on $\epsilon_{0 i}$. In this case, the conditional density is simply the product over time of $T_{i}$ univariate skew normal densities. Thus, only a single integral, as opposed to $T_{i}$ integrals, needs to be evaluated.

Recall that for each $i, \epsilon_{i t}$ is a skew normal variate with parameters $\lambda_{i t}=\left[\exp \left(\boldsymbol{z}_{u i t} \gamma_{u}\right) /\right.$ $\left.\exp \left(\boldsymbol{z}_{v i t} \boldsymbol{\gamma}_{v}\right)\right]^{1 / 2}$ and $\sigma_{i t}=\left[\exp \left(\boldsymbol{z}_{\text {uit }} \boldsymbol{\gamma}_{u}\right)+\exp \left(\boldsymbol{z}_{v i t} \boldsymbol{\gamma}_{v}\right)\right]^{1 / 2}$. Similarly, $\epsilon_{0 i}$ is a skew normal variate with parameters $\lambda_{0 i}=\left[\exp \left(\boldsymbol{z}_{u 0 i} \boldsymbol{\gamma}_{u 0}\right) / \exp \left(\boldsymbol{z}_{v 0 i} \boldsymbol{\gamma}_{v 0}\right)\right]^{1 / 2}$ and $\sigma_{0 i}=\left[\exp \left(\boldsymbol{z}_{u 0 i} \boldsymbol{\gamma}_{u 0}\right)+\right.$ $\left.\exp \left(\boldsymbol{z}_{v 0 i} \boldsymbol{\gamma}_{v 0}\right)\right]^{1 / 2}$. Thus, the conditional density of $\boldsymbol{\epsilon}_{i}=\left(\epsilon_{i 1}, \ldots, \epsilon_{i T_{i}}\right)$ is given by

$$
f\left(\boldsymbol{\epsilon}_{i} \mid \epsilon_{0 i}\right)=\prod_{t=1}^{T_{i}} \frac{2}{\sigma_{i t}} \phi\left(\frac{\epsilon_{i t}}{\sigma_{i t}}\right) \Phi\left(\frac{\epsilon_{i t} \lambda_{i t}}{\sigma_{i t}}\right) .
$$

Integrate $\epsilon_{0 i}$ (the distribution of which we know) out to get the unconditional density of $\boldsymbol{\epsilon}_{i}$

$$
f\left(\boldsymbol{\epsilon}_{i}\right)=\int_{-\infty}^{\infty}\left[\prod_{t=1}^{T_{i}} \frac{2}{\sigma_{i t}} \phi\left(\frac{\epsilon_{i t}}{\sigma_{i t}}\right) \Phi\left(\frac{\epsilon_{i t} \lambda_{i t}}{\sigma_{i t}}\right)\right] \times \frac{2}{\sigma_{0 i}} \phi\left(\frac{\epsilon_{0 i}}{\sigma_{0 i}}\right) \Phi\left(\frac{\epsilon_{0 i} \lambda_{0 i}}{\sigma_{0 i}}\right) d \epsilon_{0 i} .
$$

The log-likelihood function for the $i$-th observation of model (12) is therefore given by

$$
\begin{aligned}
& \log L_{i}\left(\boldsymbol{\theta}, \gamma_{u 0}, \gamma_{v 0}, \gamma_{u}, \gamma_{v}\right) \\
& =\log \left[\int_{-\infty}^{+\infty}\left(\prod_{t=1}^{T_{i}}\left\{\begin{array}{c}
\frac{2}{\sigma_{i t}} \phi\left(\frac{r_{i t}-\epsilon_{0 i}}{\sigma_{i t}}\right) \\
\times \Phi\left(\frac{\left(r_{i t}-\epsilon_{0 i}\right) \lambda_{i t}}{\sigma_{i t}}\right)
\end{array}\right\}\right) \frac{2}{\sigma_{0 i}} \phi\left(\frac{\epsilon_{0 i}}{\sigma_{0 i}}\right) \Phi\left(\frac{\epsilon_{0 i} \lambda_{0 i}}{\sigma_{0 i}}\right) \mathrm{d} \epsilon_{0 i}\right] \\
& =\log \left[\int_{-\infty}^{+\infty}\left(\prod_{t=1}^{T_{i}}\left\{\frac{2}{\sigma_{i t}} \phi\left(\frac{\epsilon_{i t}}{\sigma_{i t}}\right) \Phi\left(\frac{\epsilon_{i t} \lambda_{i t}}{\sigma_{i t}}\right)\right\}\right) \times \frac{2}{\sigma_{0 i}} \phi\left(\frac{\epsilon_{0 i}}{\sigma_{0 i}}\right) \Phi\left(\frac{\epsilon_{0 i} \lambda_{0 i}}{\sigma_{0 i}}\right) \mathrm{d} \epsilon_{0 i}\right],
\end{aligned}
$$

an intercept, while the variance functions do not contain $\sigma_{u 0}^{2}, \sigma_{v 0}^{2}, \sigma_{u}^{2}$, and $\sigma_{v}^{2}$, respectively. Thus, for example, if the random effects component is constant, $\boldsymbol{Z}_{v 0 i}$ is a constant and $\sigma_{v 0 i}^{2}=\exp \left(\gamma_{0}\right)$ for all $i$. 
where $\epsilon_{i t}=r_{i t}-\left(v_{0 i}+u_{0 i}\right)$. Although, following CSN, one can derive the likelihood function in closed form, we approximate the log-likelihood function and avoid using the classical ML method, which is quite complicated for the reasons mentioned above. We rely on Monte-Carlo integration as a method to approximate the integral in (17). ${ }^{6}$ For estimation purposes, we write $\epsilon_{0 i}=\left[\exp \left(\boldsymbol{z}_{v 0 i} \boldsymbol{\gamma}_{v 0}\right)\right]^{1 / 2} V_{i}+\left[\exp \left(\boldsymbol{z}_{v 0 i} \boldsymbol{\gamma}_{v 0}\right)\right]^{1 / 2}\left|U_{i}\right|$, where both $V_{i}$ and $U_{i}$ are standard normal random variables. The resulting simulated log-likelihood function for the $i$-th observation is

$$
\begin{aligned}
& \log L_{i}^{S}\left(\boldsymbol{\theta}, \boldsymbol{\gamma}_{u 0}, \boldsymbol{\gamma}_{v 0}, \boldsymbol{\gamma}_{u}, \boldsymbol{\gamma}_{v}\right) \\
& =\log \left[\frac{1}{R} \sum_{r=1}^{R}\left(\prod_{t=1}^{T_{i}}\left\{\begin{array}{l}
\frac{2}{\sigma_{i t}} \phi\left(\frac{r_{i t}-\left(\left[\exp \left(\boldsymbol{z}_{v 0 i} \boldsymbol{\gamma}_{v 0}\right)\right]^{1 / 2} V_{i r}+\left[\exp \left(\boldsymbol{z}_{v 0 i} \boldsymbol{\gamma}_{v 0}\right)\right]^{1 / 2}\left|U_{i r}\right|\right)}{\sigma_{i t}}\right) \\
\times \Phi\left(\frac{\left[r_{i t}-\left(\left[\exp \left(\boldsymbol{z}_{v 0 i} \boldsymbol{\gamma}_{v 0}\right)\right]^{1 / 2} V_{i r}+\left[\exp \left(\boldsymbol{z}_{v 0 i} \boldsymbol{\gamma}_{v 0}\right)\right]^{1 / 2}\left|U_{i r}\right|\right)\right] \lambda}{\sigma_{i t}}\right)
\end{array}\right\}\right)\right] \\
& =\log \left[\frac{1}{R} \sum_{r=1}^{R}\left(\prod_{t=1}^{T_{i}}\left\{\frac{2}{\sigma} \phi\left(\frac{\epsilon_{i t r}}{\sigma}\right) \Phi\left(\frac{\epsilon_{i t r} \lambda}{\sigma}\right)\right\}\right)\right]
\end{aligned}
$$

where $V_{i r}$ and $U_{i r}$ are $R$ random deviates from the standard normal distribution, and $\epsilon_{i t r}=r_{i t}-\left(\left[\exp \left(\boldsymbol{z}_{v 0 i} \boldsymbol{\gamma}_{v 0}\right)\right]^{1 / 2} V_{i r}+\left[\exp \left(\boldsymbol{z}_{v 0 i} \boldsymbol{\gamma}_{v 0}\right)\right]^{1 / 2}\left|U_{i r}\right|\right) . \quad R$ is the number of draws for approximating the log-likelihood function. The full log-likelihood is the sum of panel- $i$ specific log-likelihoods given in (18).

We use the results of Colombi et al. (2014) to estimate persistent and time-varying cost efficiencies. Using the moment generating function of the CSN distribution, the conditional means of $u_{0 i}, u_{i 1}, \cdots, u_{i T_{i}}$ which are, in principle, similar to the Jondrow et al. (1982) estimator, are given by:

$$
E\left(\exp \boldsymbol{t}^{\prime} \boldsymbol{u}_{i} \mid \boldsymbol{y}_{i}\right)=\frac{\bar{\Phi}_{T_{i}+1}\left(\boldsymbol{R}_{i} \boldsymbol{r}_{i}+\boldsymbol{\Lambda}_{i} \boldsymbol{t}, \boldsymbol{\Lambda}_{i}\right)}{\bar{\Phi}_{T_{i}+1}\left(\boldsymbol{R}_{i} \boldsymbol{r}_{i}, \boldsymbol{\Lambda}_{i}\right)} \times \exp \left(\boldsymbol{t}^{\prime} \boldsymbol{R}_{i} \boldsymbol{r}_{i}+0.5 \boldsymbol{t}^{\prime} \boldsymbol{\Lambda}_{i} \boldsymbol{t}\right)
$$

where $\boldsymbol{u}_{i}=\left(u_{0 i}, u_{i 1}, \ldots, u_{i T_{i}}\right)^{\prime}$ and $-\boldsymbol{t}$ is a row of the identity matrix of dimension $\left(T_{i}+1\right)$. If $\boldsymbol{-} \boldsymbol{t}$ is the $\tau$-th row, Eq (19) provides the conditional expected value of the $\tau$-th component of the cost efficiency vector $\exp \left(-\boldsymbol{u}_{i}\right)$. In particular, for $\tau=1$, we get the conditional expected value of the persistent cost efficiency.

\footnotetext{
6 Note that another approximation of (17) can be achieved by using the $M$-point Gauss-Hermite quadrature method.
} 


\section{Empirical model and data}

We follow the intermediation approach, originally proposed by Sealey and Lindley (1977), to specify inputs and outputs in our cost model (see also Casu et al. 2004). The technology of a bank is described by a translog cost function with three outputs and two inputs (Casu et al. 2013), which is

$$
\begin{aligned}
h\left(\boldsymbol{y}_{i t}, \boldsymbol{w}_{i t} ; \boldsymbol{\theta}\right) & =\beta_{0}+\sum_{k=1}^{3} \beta_{i} \log y_{k i t}+0.5 \sum_{k=1}^{3} \sum_{n=1}^{3} \beta_{k n} \log y_{k i t} \log y_{n i t} \\
& +\sum_{m=1}^{2} \alpha_{m} \log w_{m i t}+0.5 \sum_{m=1}^{2} \sum_{l=1}^{2} \alpha_{m l} \log w_{m i t} \log w_{l i t} \\
& +\sum_{k=1}^{3} \sum_{m=1}^{2} \gamma_{k m} \log y_{k i t} \log w_{m i t}+\sum_{k=1}^{3} \delta_{k} t \log y_{k i t}+\sum_{m=1}^{2} \theta_{m} t \log w_{m i t} \\
& +\sum_{k=1}^{3} \lambda_{k} R \log y_{k i t}+\sum_{m=1}^{2} \mu_{m} R \log w_{m i t}+\rho_{1} C R R_{i t}+\rho_{2} S L R_{i t}+\rho_{3} M A C_{i t} \\
& +\theta_{1} t+\theta_{2} t^{2}+\theta_{r} R+\theta_{r t} R t+v_{0 i}+u_{0 i}+v_{i t}+u_{i t},
\end{aligned}
$$

where

$c \quad$ is the sum of interest and noninterest operating cost;

$y_{1} \quad$ is interest bearing loans;

$y_{2} \quad$ is other earning assets;

$y_{3} \quad$ is fee-based income;

$w_{1} \quad$ is the price of total loanable funds and is calculated as the ratio of total interest expenditure to total loanable funds;

$w_{2} \quad$ is the price of noninterest bearing funds and is calculated as noninterest operating expense divided by total assets;

$R \quad$ is a dummy variable equal to 1 if year is larger or equal to 1998. Such specification allows to model a break in the technology following the change in regulation;

$t \quad$ is a time trend, the inclusion of which allows no neutral shift in the frontier;

$C R R$ is the capital reserve ratio, i.e., the portion of deposits that the banks have to maintain with the Reserve Bank;

$S L R$ is the statutory liquidity ratio, i.e., the portion of deposits that the bank has to maintain in form of gold, cash or other government approved securities;

$M A C$ is the contribution of banking sector to aggregate output (measured by the ratio of deposits and credit to GDP). 
and $\boldsymbol{\theta}$ is a vector of all parameters to be estimated in (20). To ensure that the regularity conditions of the cost function in equation (8) hold, we impose the usual symmetry restrictions by setting $\beta_{k n}=\beta_{n k}$ and $\alpha_{m l}=\alpha_{l m}$, and linear homogeneity in input prices by dividing total cost and $w_{2}$ by $w_{1}$.

The data comes from the Reserve Bank of India. All variables are converted to real terms using the GDP deflator. Our sample contains all state and private banks. Following previous literature, we excluded regional rural banks and foreign banks that have less than two branches, since their operations and goals differ from those of the rest of banks. Further, we keep a bank in our sample only if it is observed for at least 3 times. ${ }^{7}$ Thus, our sample contains 1,193 bank-year observations; 16 foreign, 35 private, and 27 state banks that are observed on average for 15 years with a maximum of 18 years. The sample period covers the years 1992-2009. Summary statistics of the data are presented in Table 1.

Banks of each of the three ownership types are fundamentally different and thus play different roles in the economy. Table 2 shows the number and size of a branch according to ownership category. State banks have by far the most number of branches. Private banks have on average 10 times less branches, while the number of branches of foreign banks is smaller by a factor of at least 100 .

\section{Results}

We estimate a variety of models that are special cases of our four-component heteroscedastic model. To conserve space, we report results from three models, all of which use (8) along with different specifications of the error components in (9)-(11). This implies that $\boldsymbol{\theta}$ as well as $\gamma_{v}, \gamma_{u}, \gamma_{v 0}$, and $\gamma_{u 0}$ are ownership-specific.

Model M1: No heterogeneity and persistent inefficiency (i.e., both $u_{0 i}$ and $v_{0 i}$ are set to zero for each ownership type in (9)-(11)). Further, $v_{i t}$ is homoscedastic for each ownership type but their variances differ across ownership type. Only $u_{i t}$ is heteroscedastic for each ownership type. Thus, model M1 uses determinants of inefficiency in the time-varying component of inefficiency for each ownership type. This is the model that is widely used

7 For a robustness check, we performed an alternative analysis where we allow banks that are observed at least twice. This did not change the results. The estimation is arguably more reliable as more time periods for each bank are available. 
Table 1: Descriptive statistics

\begin{tabular}{|c|c|c|c|c|c|c|c|}
\hline Variable & Ownership & Mean & $\mathrm{SD}$ & Median & Min & Max & $\mathrm{N}$ \\
\hline \multirow[t]{4}{*}{$\log c$} & All & 18.88 & 1.62 & 19.01 & 12.82 & 23.46 & 1193 \\
\hline & Foreign & 18.15 & 1.13 & 18.11 & 15.07 & 20.61 & 223 \\
\hline & Private & 17.97 & 1.52 & 18.05 & 12.82 & 22.70 & 480 \\
\hline & State & 20.11 & 1.00 & 20.07 & 17.90 & 23.46 & 490 \\
\hline \multirow[t]{4}{*}{$\log y_{1}$} & All & 16.82 & 1.68 & 16.89 & 10.79 & 21.55 & 1193 \\
\hline & Foreign & 16.15 & 1.31 & 16.18 & 13.16 & 18.98 & 223 \\
\hline & Private & 15.87 & 1.56 & 16.00 & 10.79 & 20.75 & 480 \\
\hline & State & 18.04 & 1.04 & 17.97 & 16.05 & 21.55 & 490 \\
\hline \multirow[t]{4}{*}{$\log y_{2}$} & All & 16.53 & 1.67 & 16.69 & 10.37 & 20.89 & 1193 \\
\hline & Foreign & 15.78 & 1.34 & 15.85 & 11.94 & 18.71 & 223 \\
\hline & Private & 15.55 & 1.53 & 15.65 & 10.37 & 20.06 & 480 \\
\hline & State & 17.83 & 0.91 & 17.85 & 15.64 & 20.89 & 490 \\
\hline \multirow[t]{4}{*}{$\log y_{3}$} & All & 13.40 & 1.69 & 13.60 & 6.43 & 17.81 & 1193 \\
\hline & Foreign & 13.29 & 1.50 & 13.47 & 9.12 & 16.54 & 223 \\
\hline & Private & 12.34 & 1.68 & 12.56 & 6.43 & 17.52 & 480 \\
\hline & State & 14.48 & 0.95 & 14.43 & 12.50 & 17.81 & 490 \\
\hline \multirow[t]{4}{*}{$w_{1}$} & All & 0.0723 & 0.0693 & 0.0678 & 0.0038 & 0.8125 & 1193 \\
\hline & Foreign & 0.0667 & 0.0254 & 0.0643 & 0.0240 & 0.1574 & 223 \\
\hline & Private & 0.0808 & 0.1066 & 0.0669 & 0.0038 & 0.8125 & 480 \\
\hline & State & 0.0665 & 0.0133 & 0.0688 & 0.0379 & 0.1026 & 490 \\
\hline \multirow[t]{4}{*}{$w_{2}$} & All & 0.0268 & 0.0231 & 0.0246 & 0.0022 & 0.2813 & 1193 \\
\hline & Foreign & 0.0278 & 0.0160 & 0.0260 & 0.0057 & 0.1470 & 223 \\
\hline & Private & 0.0284 & 0.0340 & 0.0229 & 0.0022 & 0.2813 & 480 \\
\hline & State & 0.0247 & 0.0064 & 0.0252 & 0.0056 & 0.0399 & 490 \\
\hline \multirow[t]{4}{*}{$\log (\overline{\mathrm{TA} / \# \mathrm{br}})$} & All & 12.59 & 1.55 & 11.93 & 10.18 & 16.46 & 1193 \\
\hline & Foreign & 15.20 & 0.66 & 15.23 & 13.55 & 16.26 & 223 \\
\hline & Private & 12.17 & 1.31 & 11.77 & 10.18 & 16.46 & 480 \\
\hline & State & 11.82 & 0.31 & 11.77 & 11.42 & 13.97 & 490 \\
\hline $\log (\overline{\text { Credit/GDP }})$ & All & -1.28 & 0.09 & -1.27 & -1.60 & -0.75 & 1193 \\
\hline$C R R$ & All & 8.86 & 3.70 & 7.63 & 4.60 & 15.00 & 1193 \\
\hline$S L R$ & All & 27.22 & 4.21 & 25.00 & 24.00 & 38.50 & 1193 \\
\hline$M A C$ & All & -0.61 & 0.37 & -0.61 & -1.28 & 0.03 & 1193 \\
\hline
\end{tabular}

in the literature (see, for example, Evanoff and Ors, 2008, Casu et al., 2013 and Das and Kumbhakar, 2012). ${ }^{8}$ In our framework M1 is the most restrictive model.

8 Note that the determinants of inefficiency can also be introduced via the pre-truncated mean. We considered it via the pre-truncated variance of $u_{i t}$ to make the analysis simple. 
Table 2: Distribution of number of branches by ownership type

\begin{tabular}{lrrrrrrr}
\hline Ownership & N & StDev & Min & Q1 & Mean & Q3 & Max \\
\hline Foreign & 223 & 18 & 2 & 3 & 13 & 18 & 90 \\
Private & 480 & 173 & 2 & 66 & 200 & 273 & 1408 \\
State & 490 & 1709 & 157 & 744 & 1720 & 2048 & 11447 \\
\hline
\end{tabular}

Model M2: This is the standard four component model that has all four error components for each ownership type in (9)-(11). However, all the error components are homoscedastic for each ownership type, but the variance of each error component differs across ownership type.

Model M3: This is the heteroscedastic four component model in which all the error components for each ownership type in (9)-(11) are heteroscedastic. Thus, this model includes determinants of both persistent and time-varying inefficiency as well as determinants of persistent and time-varying production risk. M3 is the most general model with both M1 and M2 nested in it.

\subsection{Testing model specification}

Table A.1 in Appendix A presents estimated coefficients of the translog model (M1-M3) for each ownership type. ${ }^{9}$ Production risk in the time-varying noise component $\left(v_{i t}\right)$ is introduced by allowing the variance of $v_{i t}$ to depend on the cash reserve ratio (CRR). Similarly the variance of the time-invariant production risk component $\left(v_{0 i}\right)$ is allowed to depend on the average (over time) size of a branch of a bank (assets per branch). The determinants of time-varying inefficiency are the time trend, the reform dummy and their interactions. In the absence of natural time-invariant determinant variables that are out of banks' control, we chose the mean (over time) of credit of banking system to GDP ratio as a determinant of time-invariant inefficiency. The determinants of inefficiency and production

9 We have also estimated models where the technology in M1-M3 are assumed to be the same for all banks in all ownership types. However, this specification was rejected by the likelihood ratio test. The results are available upon request. 
risk variables are jointly statistically different from zero in all models for all ownership types. $^{10}$

The likelihood $(L R)$ statistic for testing Model M3 against Model M2 is 182.1, which exceeds the critical value of a mixed $\chi_{21}^{2}$ distribution ${ }^{11}$ of 30.3 at the $1 \%$ significance level. This implies that specification M3 is preferred to that of M2. We also reject the null hypothesis that there are no determinants of production risk and no bank heterogeneity or persistent inefficiency (M3 against M1) based on an $L R$ statistic of 179.3 (critical value of a mixed $\chi_{15}^{2}$ is 29.93 at the $1 \%$ significance level). We cannot directly test non-nested models M1 and M2, but if we assume that there are no determinants of the time-varying inefficiency (model M1 without determinants), the $L R$ statistic is 74.15 which is larger than the critical value of a mixed $\chi_{6}^{2}$ at the $1 \%$ significance level (16.07), meaning that both bank heterogeneity and persistent inefficiency cannot be ignored.

Model M3 is therefore the preferred model. A model containing only two time-varying components (M1), which is typically estimated (see Das and Kumbhakar 2012, among others), is misspecified. Similarly, the homoscedastic four component model (M2) is also misspecified. Next, we briefly describe the main features of regulation in Indian banking over a two decade period and analyze the effect of change of regulation on RTS, TC and efficiencies.

\subsection{Deregulation and re-regulation}

Before examining the impact of deregulation and re-regulation, we put the story in historical perspective. The financial liberalization process in India was initiated during the early 1990s, and it was primarily aimed at making the Indian financial sector efficient, competitive, productive and profitable. The early phase of reforms (known as the first generation reform which started with the recommendation of Narasimham Committee-I) was aimed at the promotion of competition. Initially, it created an environment for banks to overcome the external constraints related to an administered interest rate regime, high levels of reserve requirements and credit allocation to certain sectors. The overwhelming dominance of the

\footnotetext{
${ }^{10}$ As mentioned before, one can consider a variety of interesting special cases of model M3 - not only in the choice of different $z$ variables in the variances of different error components but also making some of the error components for some ownership types homoscedastic. To conserve space, we are not reporting results from all these models.

${ }^{11}$ Given that the zero restrictions are on the boundary of the parameter values, the LR statistics has a mixed $\chi^{2}$ distribution (see Coelli 1995).
} 
state owned banks in the system was gradually brought down and these banks were allowed to raise additional capital from the stock market. Diversification of ownership also led to greater market discipline and increased accountability. In order to enhance efficiency and productivity in the banking sector through competition, the private sector and the foreignbanks were allowed more liberal entry. At the same time, consolidation and restructuring in the form of mergers and relaxed branch licensing policy had initially improved the overall profitability of the banking sector.

The downfall of such liberalization was the building up of non-performing assets. This was one of the reasons deregulation was reconsidered, and the emphasis was switched to the stability of financial systems in general, with a particular focus on the soundness of banks (re-regulation). The recommendation of Narasimham Committee-II (1998) was to phase out the priority sector lending, take control of the non-performing assets and tighten the capital adequacy norms. Banks had to deal with these introductions on their own since help from the state in the form of budgetary provisions was ruled out. One of the goals of re-regulation was improvement of performance. The principles of re-regulation were applied to banks of all ownership types without exceptions.

In the following sub-sections we analyze the effect of this shift in policy (from deregulation to prudential re-regulation in the interest of long-run stability of the banking system) on scale economies, technical change and the efficiency of banks of all ownership types. Here we report results from Model M3 which is the most flexible model.

\subsubsection{Returns to scale}

Given data for each bank and each time period, as well as parameter estimates of the cost function in (8), we calculate the RTS, which is defined as the reciprocal of the sum of cost elasticities with respect to outputs from the cost function, viz.,

$$
R T S_{i t}=\left(\sum_{k=1}^{3} \frac{\partial \log c_{i t}}{\partial \log y_{k i t}}\right)^{-1}
$$

Economies of scale are typically calculated as one minus the sum of cost elasticities. The logic behind estimating RTS is to check whether a simultaneous increase in all outputs by $1 \%$ leads to an increase in total costs by $1 \%$ (constant returns to scale-CRS), less than $1 \%$ (increasing returns to scale) or more than $1 \%$ (decreasing returns to scale). CRS means that a bank operates at the most productive scale size given the technology. Increasing (decreasing) returns to scale (IRS and DRS) implies economies (diseconomies) of scale. The 
presence of scale economies suggests that a bank can benefit from expansion, thus justifying policy aimed towards mergers and de-regulation. Existing diseconomies of scale of a large bank might in turn be used to argue in favor of tighter control of its size.

For each data point, we calculated RTS and their standard errors using the Delta method. This allows us to calculate the $95 \%$ confidence interval of RTS. We classify RTS as 'CRS' if the $95 \%$ confidence interval contains 1 . Similarly, returns to scale is 'DRS' ('IRS') if the calculated RTS is smaller (larger) than the lower (upper) bound of the confidence interval.

Figure 1 reports the results in four panels. The upper panel plots the distributions of RTS by ownership type for all time periods. The three lower panels show plots of the distribution of RTS before (solid curves and vertical lines) and after (dotted curves and vertical lines) prudential re-regulation policy was enacted. In all panels the thin solid vertical line represents CRS.

It is clear from the figures that the distribution of RTS of foreign banks has the largest spread among all banks. Many foreign banks have diseconomies of scale (81 banks in various years). In the post re-regulation period, the number of "DRS" foreign banks increased from 17 to 64 , which is confirmed by the shift in the RTS distribution to the left. The number of foreign banks that have efficient scales doubled over time from 41 to 82 .

Most of the private banks have economies of scale mainly because these are generally smaller than the state-owned and foreign-owned banks. Over time, the distribution has shifted to the right, implying that in the period of deregulation (before 1998) private banks were exploiting their economies of scale, but during the re-regulation period the potential for economies of scale increased for many of the private banks. The number of private banks operating under IRS increased from 68 to 279 in the post re-regulation period. Only two private banks were operating under DRS.

The distribution of RTS of state banks is concentrated around 1. The median value of returns to scale is indistinguishable from unity, suggesting that the SOBs exhibit roughly constant returns to scale. Some SOBs had economies of scale during deregulation, but the distribution of RTS has shifted leftward over time. The number of state banks with economies of scale decreased from 37 to 10 during the post re-regulation period. While we do not observe a single 'DRS' state bank during deregulation, 36 SOBs operated under DRS in the post re-regulation period. The number of state banks operating at optimal scales (CRS) increased from 125 to 282.

Figure 2 shows the evolution of (average) RTS for banks of the three ownership types. The RTS of private banks was on average 1.02, jumped to 1.03 around 1998, and largely 

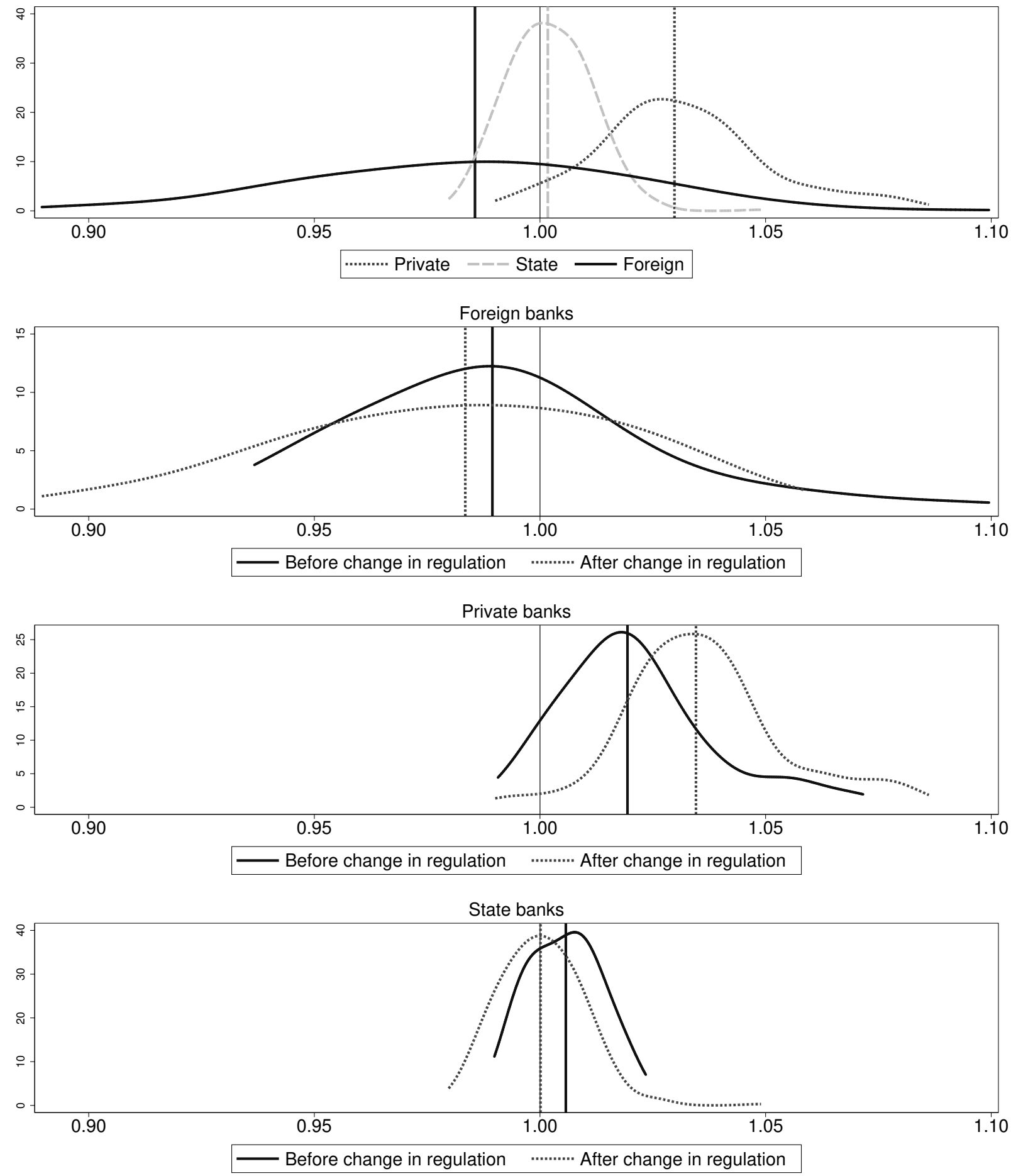

Figure 1: Distributions (estimated kernel densities) of returns to scale (M3) Notes: Vertical lines are respective medians

remained at that level until 2009. The RTS of SOBs is about 1 on average over the whole time span. Returns to scale of foreign banks, on average, declined from about 1 in 1992 to 


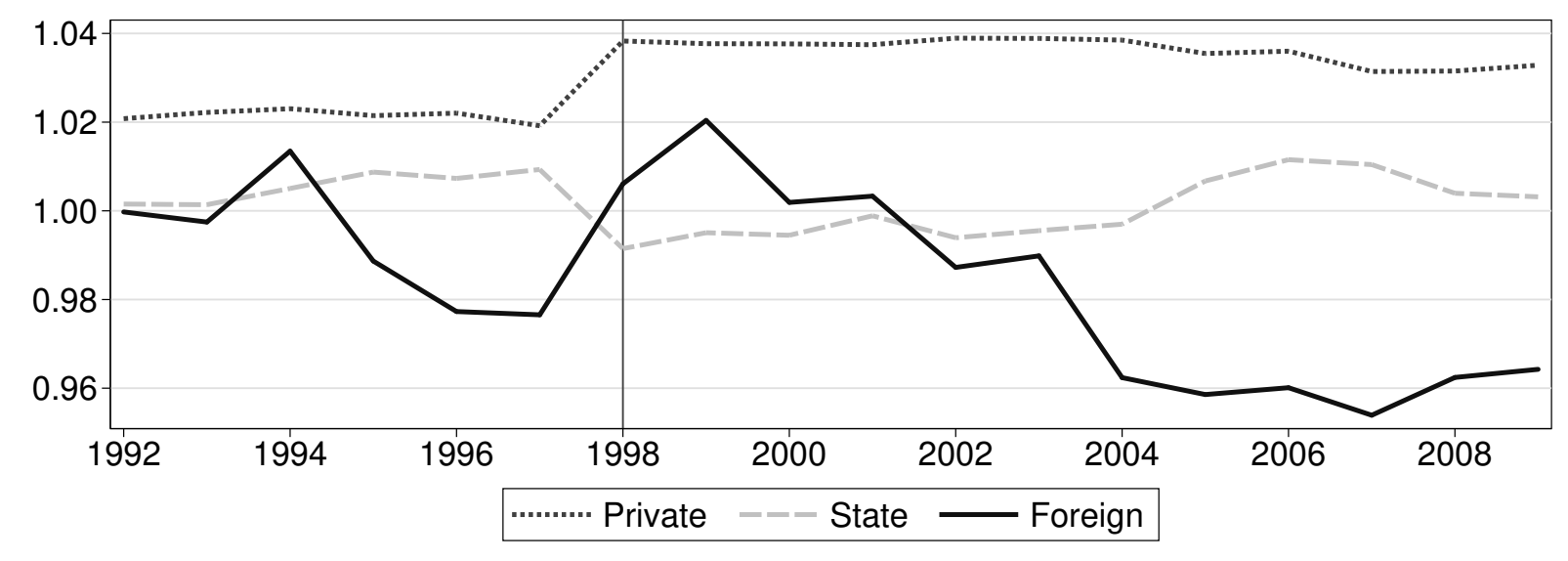

Figure 2: Time series plot of average RTS by ownership type (M3) Notes: Vertical line is year 1998

Table 3: Proportion of RTS by ownership type before and after change in regulation (M3)

\begin{tabular}{|c|c|c|c|c|c|c|c|c|c|}
\hline & \multicolumn{3}{|c|}{ Foreign } & \multicolumn{3}{|c|}{ Private } & \multicolumn{3}{|c|}{ State } \\
\hline & CRS & DRS & IRS & $\mathrm{CRS}$ & DRS & IRS & CRS & DRS & IRS \\
\hline Befo & 0.641 & 0.266 & 0.094 & 0.561 & 0.000 & 0.439 & 0.772 & 0.000 & 0.228 \\
\hline After & 0.516 & 0.403 & 0.082 & 0.135 & 0.006 & 0.858 & 0.860 & 0.110 & 0.030 \\
\hline
\end{tabular}

0.98 just before the change in regulation. In the post re-regulation period, RTS first increased to 1.02 , leveled at 1 in 2003 and then dropped to 0.96. Thus, the shift of distribution we observed in Figure 1 has mainly occurred from 2004 onwards, implying that the effect of the change in regulation was not instantaneous.

We further look at the proportion of banks operating at different RTS before and after the change in regulation. Table 3 suggests that the proportion of foreign banks operating under IRS remained the same. The decline in the share of foreign banks having CRS is almost entirely compensated by an increase in the proportion of foreign banks operating below the optimal scale.

The proportion of private banks operating under DRS changed minimally (recall that only 2 private banks operated under DRS after 1998 versus 0 before 1998). The proportion of private banks operating under IRS doubled from $43 \%$ to $86 \%$. The opposite is true for the SOBs. The portion of state banks having economies of scale has dropped from $23 \%$ to $3 \%$. The proportion of state banks operating under diseconomies of scale is $11 \%$. In 
the post re-regulation period, a larger proportion of state banks were operating under an efficient scale.

\subsubsection{Technical change}

Technical change in a cost function is cost diminution over time, ceteris paribus. It is estimated from $\partial \log (T C) / \partial t$ (e.g., McKillop et al. 2004). Given data and parameter estimates, technical change from equation (8) is bank- and time-specific. If technical change in negative (positive), the total costs decline (increase) over time, ceteris paribus. To make it more intuitive, we reversed the sign of the technical change so that a positive value implies technical progress, while a negative sign means technical regress. Figure 3 shows distributions of technical change by ownership type as well as pre- and post regulation change. In all panels, the thin solid vertical line represents no technical change. Vertical lines are the medians of their respective distributions. The figures suggest that, on average, banks of all ownership type have experienced technical progress. But there are also banks in each ownership group that experienced technical regress.

Figure 4 shows the average technical change by ownership type over time. From 1992 to 1997, average technical change declined for all. More specifically, during the deregulation period, state owned banks experienced, on average, technical regress at a rate of about $2 \%$ per annum. On the other hand, foreign banks, on average, started with technical progress of about $2 \%$ and then continuously declined until 1997. The same is true for private banks, although the decline was not as pronounced as for foreign banks. The distribution for foreign banks shifted to the right after re-regulation to a large extent. In 1998, the average technical progress was about $8 \%$. However, foreign banks were not able to maintain this high level, and average technical progress reached about zero by 2009. We observe the same declining pattern of technical progress for both private and state banks, although the shift in distribution was not as big as that for the foreign banks. Private banks, on average, experienced technical regress towards the end of the sample period. On average, technical change in the post re-regulation period for private banks is about $1 \%$ compared to about $4 \%$ for foreign banks. Only state banks enjoyed technical progress of about $2 \%$ per annum during the whole period of re-regulation. 

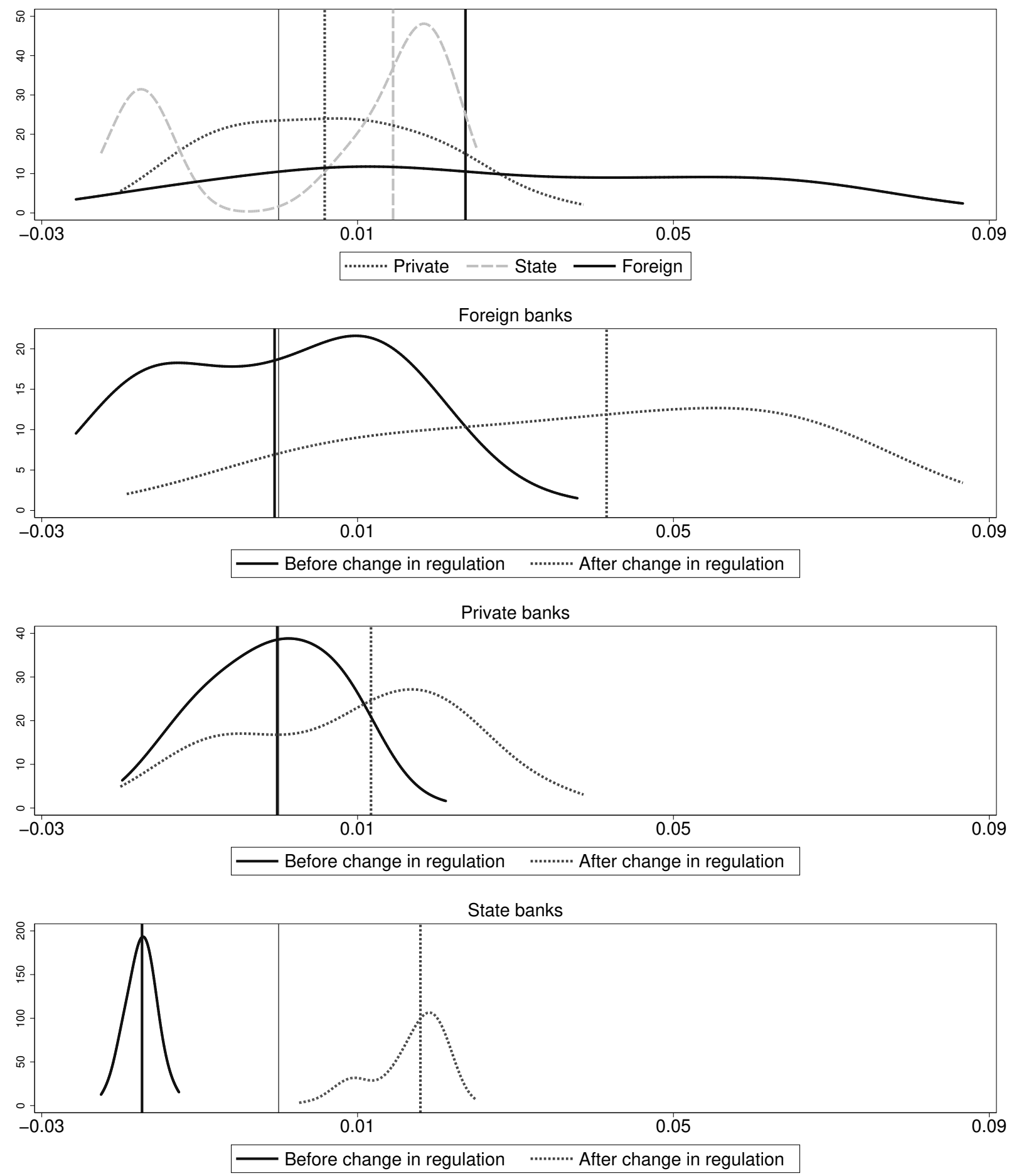

Figure 3: Distributions (estimated kernel densities) of technical change (M3) Notes: Vertical lines are respective medians 


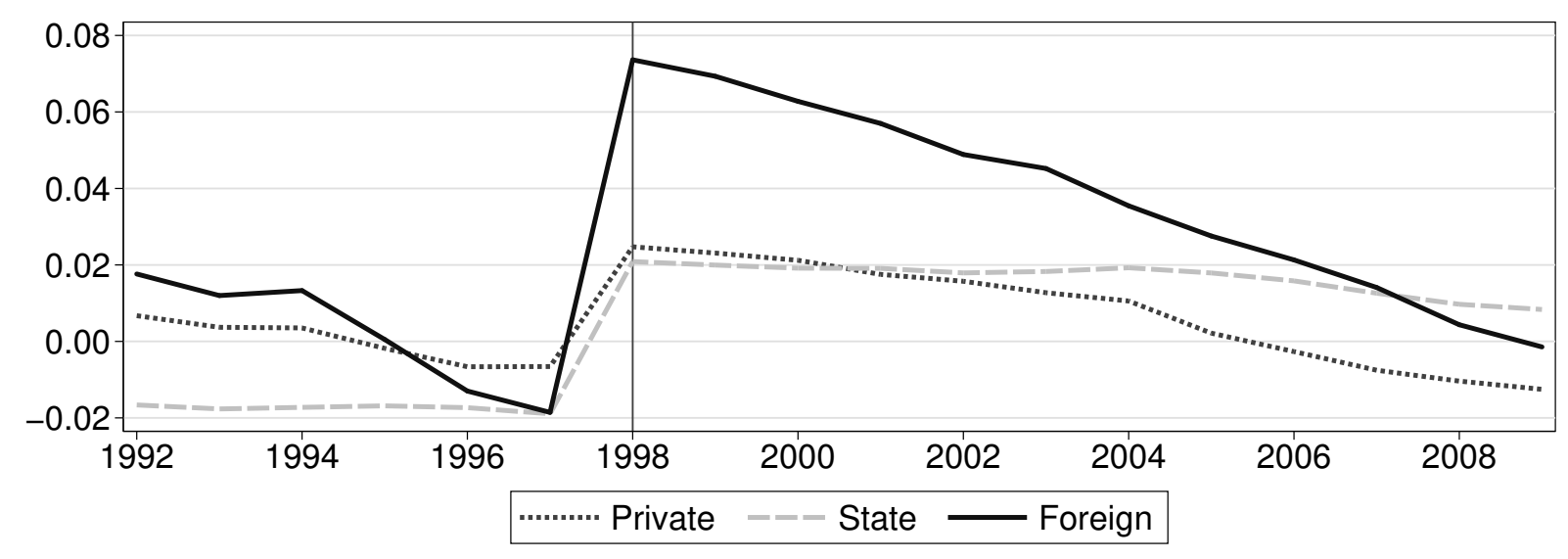

Figure 4: Time series plot of average technical change by ownership type (M3) Notes: Vertical line is year 1998

\subsubsection{Time-varying cost efficiency}

In almost all the banking efficiency studies that we cited earlier, time-varying efficiency is the only inefficiency. Time-varying efficiency models give an estimate of absolute values of cost efficiency as well as the rate of efficiency change. Here we use both: the absolute values are used to compare bank performance before and after the change in regulation, and we also compare these across ownership types. Efficiency change results show whether the inefficient banks are closing the efficiency gap, and whether banks of some ownership types are closing the gap faster than others. Figure 5 shows the distributions of time-varying cost efficiency by ownership type. It is worth noting that because banks of different ownership types have different cost frontiers, cost efficiency is measured relative to their own frontiers and are therefore not comparable across ownership types. We compare efficiency distributions before and after the change in regulation for each ownership group separately.

Foreign banks were mostly efficient before 1998 relative to their cost frontier. But the least efficient banks had an efficiency level of 0.65. Average efficiency decreased from 0.91 during the deregulation era to 0.85 in the post re-regulation years. The whole distribution shifted to the left during the re-regulation era, with a long left tail. Thus, the foreign banks not only became less efficient on average, but the proportion of banks with low level efficiency also increased.

Before the change in regulation, all private banks had a level of efficiency of around 0.97. After 1998, the average efficiency level declined slightly to 0.94. Some banks became highly inefficient. The lowest portion of the distribution shifted to the left. The fifth percentile 


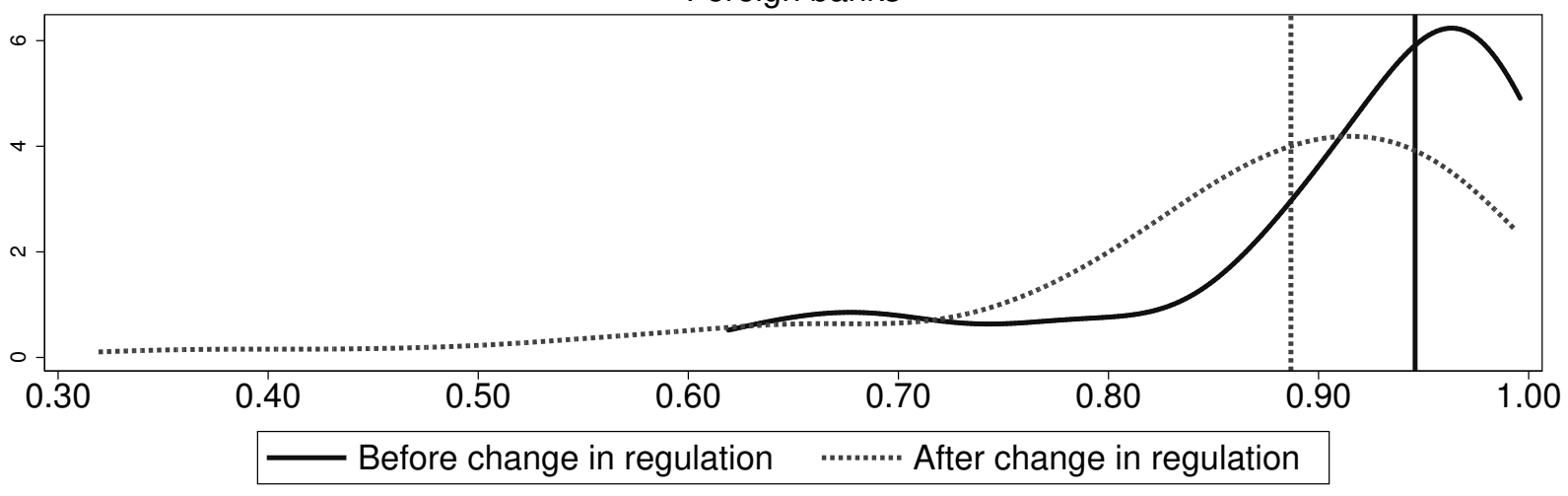

Private banks

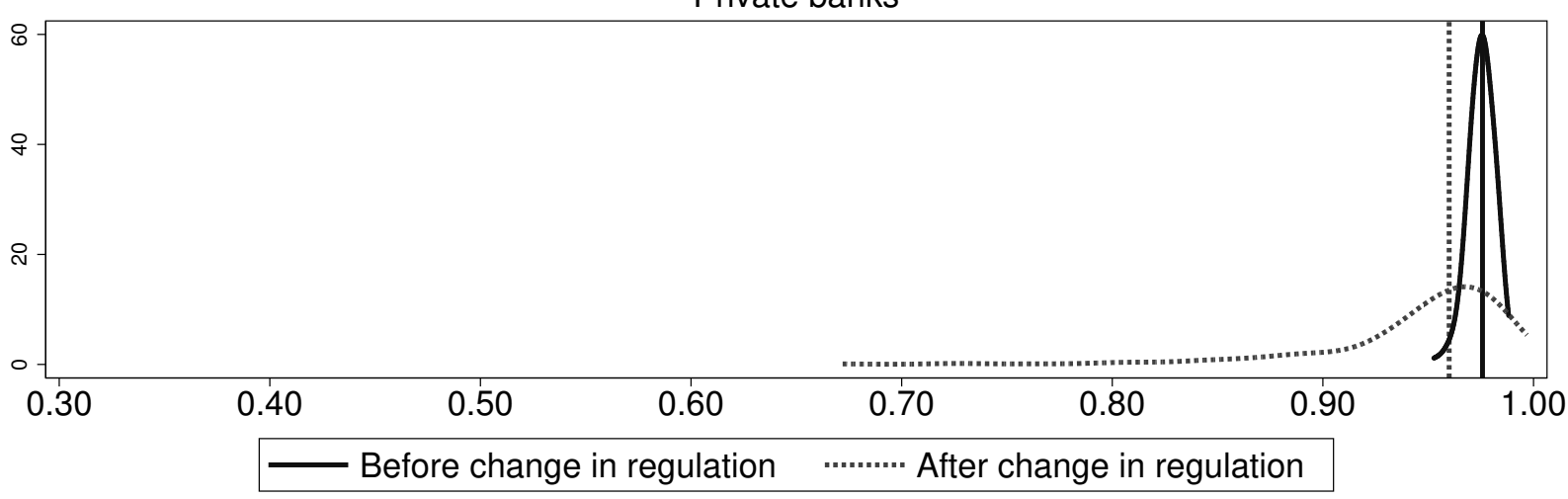

State banks

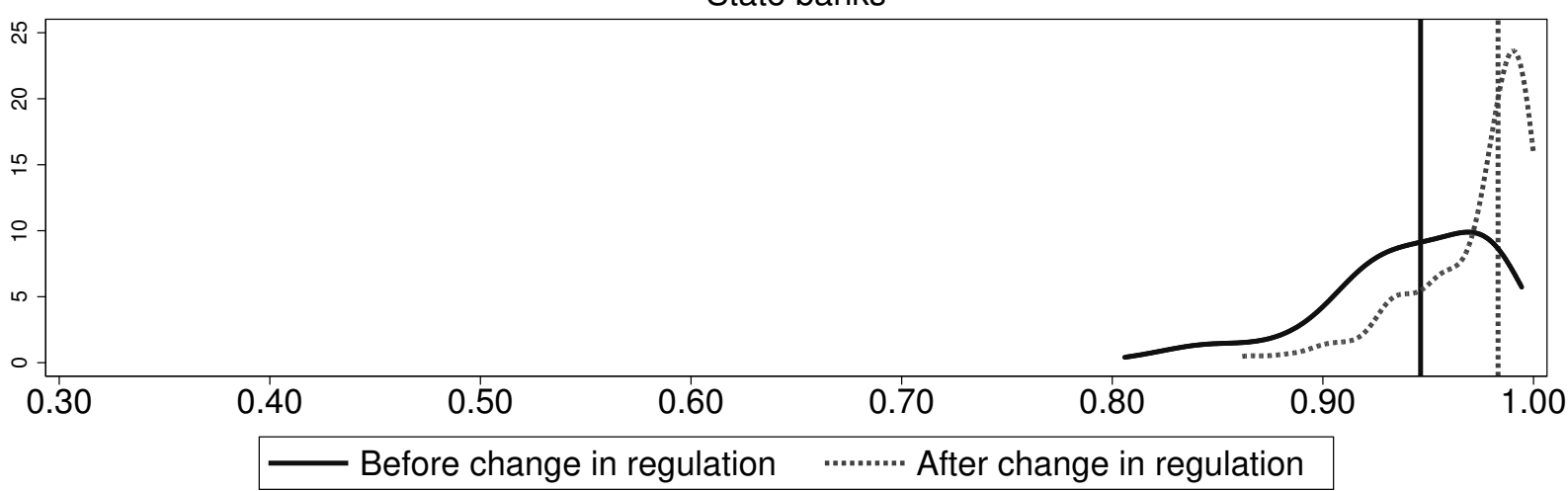

Figure 5: Distributions (estimated kernel densities) of time-varying cost efficiency (M3) Notes: Vertical lines are respective medians

of the efficiency distribution before 1998 was 0.96 and decreased to 0.85 in the post reregulation period.

While both private and foreign banks were hit hard by the change in regulation, state banks seem to have benefited from it. The entire distribution of time-varying cost efficiency 
moved to the right. The fifth percentile of the distribution increased from 0.85 before 1998 to 0.91 after 1998. On average, the efficiency of state banks increased from 0.94 to 0.97 .

We now consider efficiency change over time holding everything else fixed. Since the time-varying cost efficiency is $\exp \left(-u_{i t}\right)$, the rate of change in it due to a change in $z_{k}$ (labeled as CEC) is given by

$$
\mathrm{CEC}: \equiv \Delta \mathrm{CE}_{i t}=-\frac{\partial u_{i t}}{\partial z_{k}} \approx-\frac{\partial E\left(u_{i t}\right)}{\partial z_{k}}=-\sqrt{\frac{2}{\pi}} \frac{\partial \sigma_{u i t}}{\partial z_{k}}
$$

Under the assumption $\sigma_{u i t}^{2}=\exp \left(\boldsymbol{z}_{u i t} \boldsymbol{\gamma}_{u}\right)$, Equation (22) becomes

$$
-\sqrt{\frac{2}{\pi}} \frac{1}{2} \gamma_{u k} \exp \left(\frac{1}{2} \boldsymbol{z}_{u i t} \boldsymbol{\gamma}_{u}\right)
$$

In $\mathrm{M} 3$ we specify $\sigma_{u i t}^{2, \mathrm{OWN}}=\exp \left(\gamma_{u 0}^{\mathrm{OWN}}+\gamma_{u 1}^{\mathrm{OWN}} t+\gamma_{u 2}^{\mathrm{OWN}} t^{2}+\gamma_{u 3}^{\mathrm{OWN}} R t+\gamma_{u 4}^{\mathrm{OWN}} R\right)$, where OWN is the ownership type. Therefore

$$
\begin{aligned}
\Delta \mathrm{CE}_{i t}^{\mathrm{OWN}} & \approx-\sqrt{\frac{2}{\pi}} \frac{1}{2}\left(\gamma_{u 1}^{\mathrm{OWN}}+2 \gamma_{u 2}^{\mathrm{OWN}} t+\gamma_{u 3}^{\mathrm{OWN}} R\right) \\
& \times \exp \left(\frac{1}{2}\left[\gamma_{u 0}^{\mathrm{OWN}}+\gamma_{u 1}^{\mathrm{OWN}} t+\gamma_{u 2}^{\mathrm{OWN}} t^{2}+\gamma_{u 3}^{\mathrm{OWN}} R t+\gamma_{u 4}^{\mathrm{OWN}} R\right]\right)
\end{aligned}
$$

Plugging data into (24), we obtain 18 distinct values of CEC for foreign, private, and state owned banks. Figure 6 shows the evolution of CEC over time for banks by type of ownership. The change in regulation had qualitatively the same adverse effect on CEC for banks in each ownership group. The effect was different quantitatively.

The efficiency gap had been closing during deregulation for foreign banks. The situation reversed with the change in regulation, whereby the rate of change became negative in 1998. It took foreign banks 6 years to alter this negative trend. In 2004, foreign banks started to close the efficiency gap and efficiency continued to increase to the rate of $2.8 \%$ in 2009 .

In the case of private banks, the rate was close to zero before the change in regulation and then dropped, but not by as much as for foreign banks. During the period of prudential regulation, the rate of cost efficiency change was continuously increasing and reached $1.8 \%$ in 2006 but then declined to $0.7 \%$ by the end of the observation period.

The CEC for state banks before 1998 was very similar to that of private banks. In comparison to other banks, the slow-down of the rate for state banks around the time of regulation change was minimal. The rate was positive but very low - about $0.5 \%$ per year. 


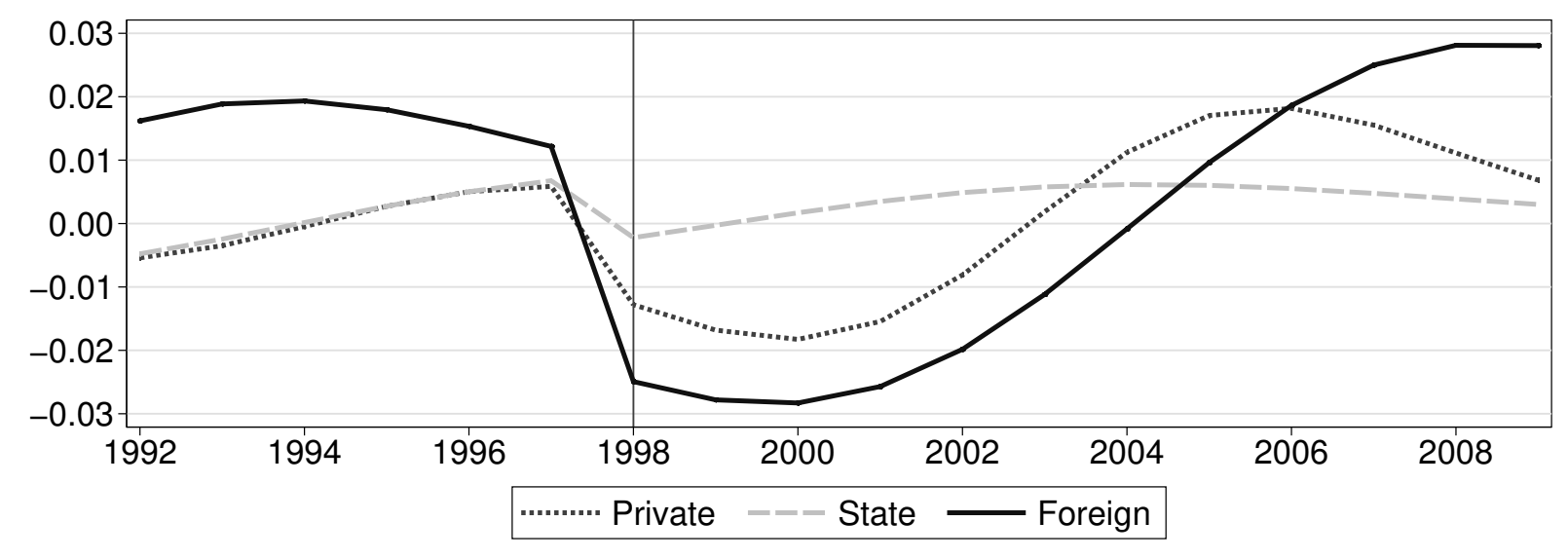

Figure 6: Time series plot of rate of change of time-varying cost efficiency by ownership type (M3)

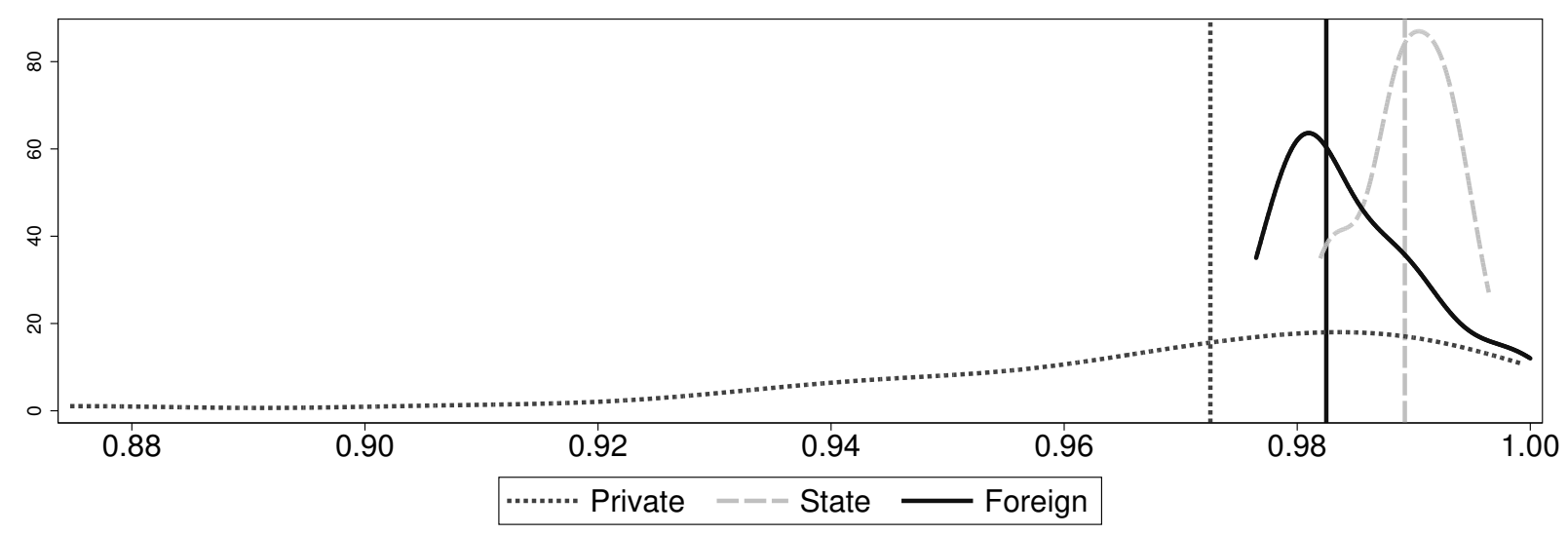

Figure 7: Persistent cost efficiency (M3)

\subsubsection{Persistent cost efficiency}

In models M2 and M3, we can separate persistent inefficiency from time-varying inefficiency, although in M2 both are purely random (i.e., neither cross-sectional nor temporal variations in them is explained by any factors). Figure 7 shows distributions of persistent efficiency in M3. Both private and state banks are nearly fully cost efficient (the average persistent cost efficiency is about 0.98), i.e., they have negligible persistent inefficiency. The average persistent cost efficiency of foreign banks is 0.97 . Persistent efficiency of some private banks is less than $90 \%$. This is not surprising since the slope parameter of the $\sigma_{u 0}^{2}$ function for private banks is statistically significant. 


\subsubsection{Overall efficiency}

Model M1 ignores persistent efficiency, so that time-varying efficiency is also an overall efficiency. In model M3, the overall cost efficiency of a bank is a product of persistent and time-varying efficiencies. Figure 8 shows distributions of overall efficiency in M3 before and after the change in regulation by ownership type. We again note that overall efficiency cannot be compared across ownership types since banks use different frontiers, but we can make comparisons of efficiency distributions during de- and re-regulation for banks of each ownership group. The distributions of overall efficiencies for foreign and state banks are virtually indistinguishable from those of time-varying efficiencies (Figure 5). Figure 8 suggests, however, that the difference in overall efficiency of private banks before and after the change in regulation is much smaller than that of time-varying efficiency. The median value of overall efficiency has declined only slightly from 0.947 to 0.932 .

\subsubsection{Production risk}

One of the advantages of our model (M3) is that we incorporated determinants of production risks in both the time-invariant and time varying components, i.e., $\sigma_{v 0 i}^{2}$ and $\sigma_{v i t}^{2}$. The presence of these determinants allows us to analyze their effects on production risks. Given our specification of the $\sigma_{v 0 i}^{2}$ and $\sigma_{v i t}^{2}$ functions, the coefficient of the cash reserve ratio can be interpreted as the elasticity of time-varying production risk with respect to the cash reserve ratio, while the coefficient of the average size of a branch can be interpreted as the elasticity of time-constant production risk with respect to the average size of a branch.

The size of a branch's elasticity of the time-constant risk is positive for all ownership groups. It is the largest for foreign banks and is the smallest for private banks, although it is only statistically significant for private banks. Roughly speaking, these results suggest that the size of a branch has a negative effect on the production risk for private banks, but has no effect for foreign or state banks. Note that the intercepts and slopes of the $\sigma_{v 0 i}^{2}$ and $\sigma_{v i t}^{2}$ functions are jointly significant for banks of each ownership type, meaning that time-constant and time-varying risks are present for all banks. The CRR elasticity of timevarying risk is negative but insignificant for foreign and state banks. For private banks, it is positive and statistically significant. These results imply that changes in CRR increase the time-varying production risk for a private bank, but they do not affect foreign and state banks. 


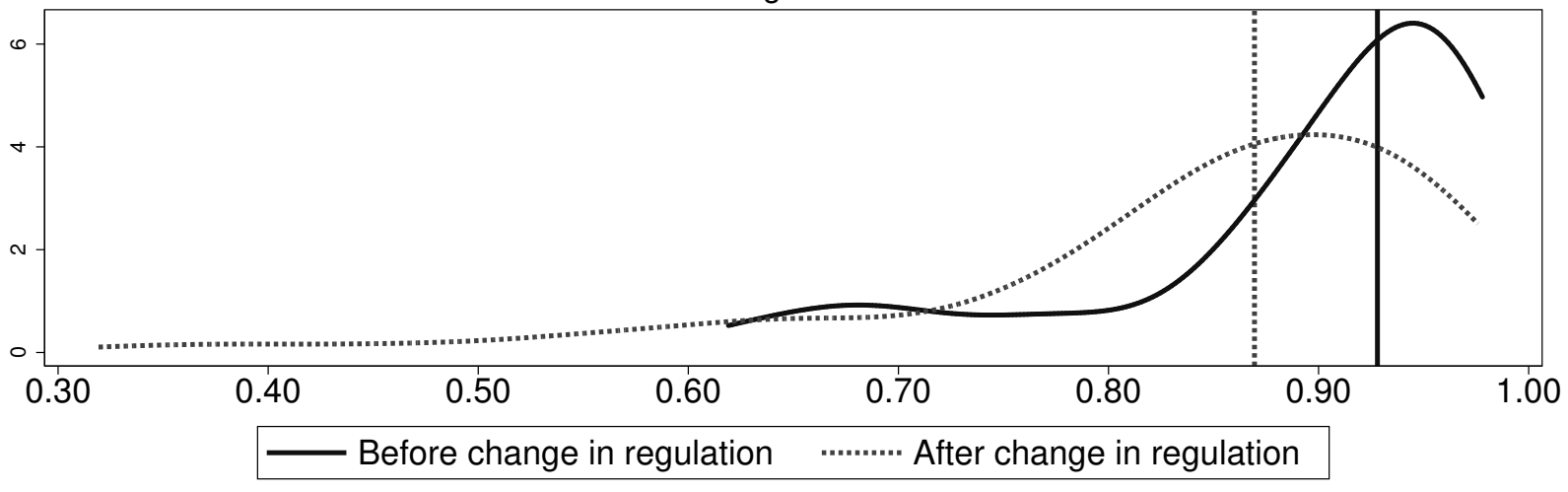

Private banks

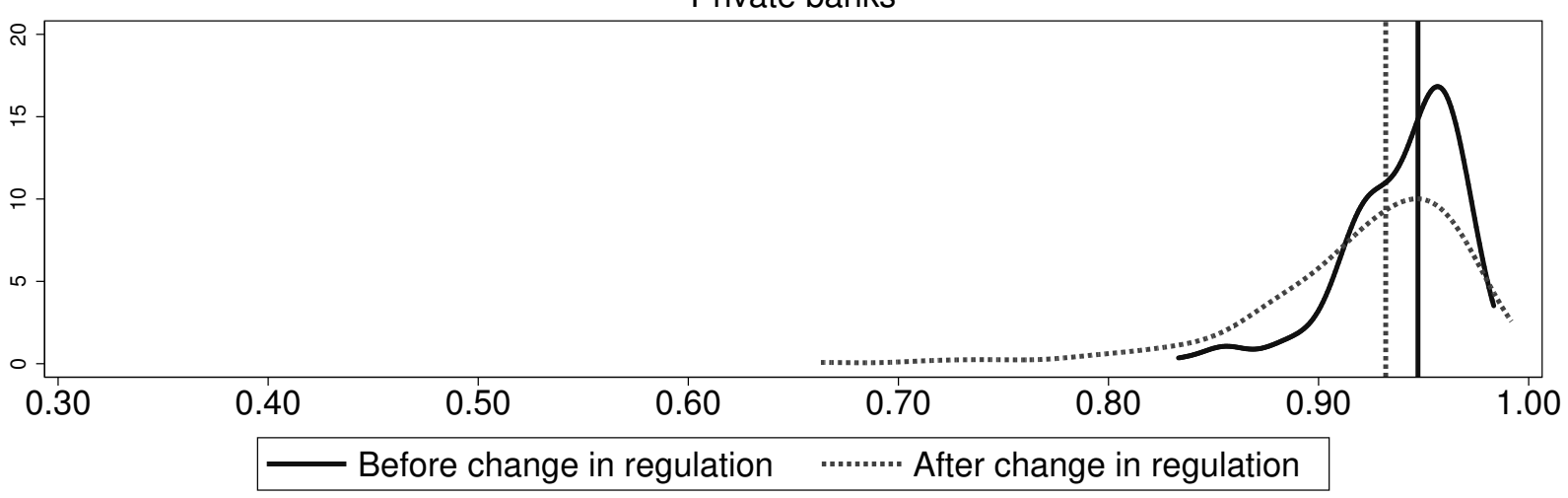

State banks

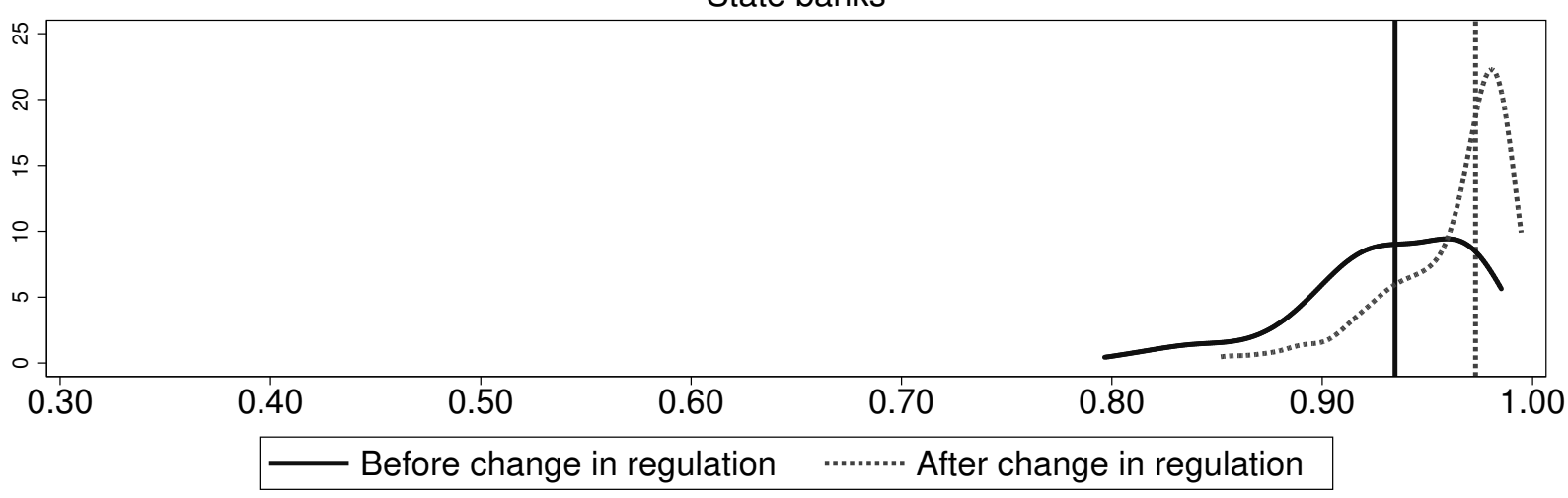

Figure 8: Distributions (estimated kernel densities) of overall cost efficiency (M3) Notes: Vertical lines are respective medians

\subsubsection{Regulation in other Asian economies}

Since in many Asian countries the banking sector regulation has followed a similar pattern over the period from 1990 to 2000, some assessment and comparisons to findings in the literature are informative. The primary goal of deregulation in the beginning of 1990s was 
strengthening competition and improving the efficiency of financial intermediaries. Following the 1997 crisis, the focus of banking regulation is to protect the banking sector and hence the economy from excessive risk taking by banks. For Pakistan, Di Patti and Hardy (2005) found that privatized banks increase their efficiency right after privatization. On average, state banks marginally improved their cost efficiency following two regulations in 1993 and 1998, while cost efficiency of foreign banks remained virtually the same. On the other hand, Burki and Niazi (2010) showed that banking efficiency in Pakistan fell following induction of the reform, but then rebounded. They also show that performance of foreign banks worsened toward the end of consolidation stage of the reform. Jaffry et al. (2013) compared average performance of commercial banks in Pakistan and India from 1985-2003. In both countries, banks became less efficient right after the introduction of the reform with subsequent improvement towards the end of the observed period.

Liberalization, structural changes and bank restructuring have also been introduced in other South East Asian countries. The empirical evidence regarding the effect of these changes is inconclusive. Hao et al. (2001) argued that the financial deregulation of 1991 appeared to have little or no significant effect bank efficiency of private Korean banks. Okuda et al. (2002) documented technological regress of Malaysian banks similar to what we found for Indian banks. Okuda and Mieno (1999) and Okuda et al. (2002) found that financial liberalization increased the variance of Thai and Malaysian bank inefficiency. Williams and Intarachote (2002) found that bank profit efficiency decreased at an increasing rate following financial liberalization in Thailand between 1990 and 1997, concluding that deregulationinduced expansion of banking activity ultimately increases financial fragility. Chen et al. (2005) claimed that the financial deregulation of 1995 improved cost efficiency of Chinese banks.

Comparing five South East Asian countries, Indonesia, Korea, Malaysia, the Philippines, and Thailand from 1990-2003, Williams and Nguyen (2005) maintained that the effect of privatization on profit efficiency was positive and relatively prompt. The effect of foreign acquisition on profit efficiency was slower. Casu et al. (2016) analyzed the effect of regulatory reforms on bank cost efficiency on a panel dataset of eight Asian countries. They argued that deregulation had positively influenced bank performance in general. Furthermore, liberalization policies such as privatization and removal of restrictions on foreign acquisitions had positive impact on technological progress. Re-regulation, on the other hand, did not appear to have influenced cost technology but cost efficiency tended to be lower after prudent policies were introduced. 


\section{Conclusion}

In this paper, we propose a panel stochastic cost frontier model to investigate the effects of deregulation and re-regulation of Indian banks of different ownership types on RTS, technical change and efficiency. Our model allows ownership-specific cost frontiers that (i) control for random bank-effects (bank heterogeneity) and (ii) separate persistent inefficiency from time-varying inefficiency. Furthermore, the variances of random bank-effects and the noise component (labeled as production risk) are allowed to be heteroscedastic (function of covariates) for each ownership type. Similarly, we allow factors to explain persistent and time-varying inefficiency components. Results from this model are compared with a similar model that has all the components, but these components are homoscedastic. We also use another restrictive model that allows determinants of time-varying inefficiency, but that does not allow bank-effects and persistent inefficiency. The variance of the noise term in this model is assumed to be homoscedastic (no production risk).

Our results suggest that banks with different ownership types have their own technology. Thus we caution against studies that use a common technology for banks and other financial institutions without testing whether technologies are different. We further find that it is important to account for bank heterogeneity, otherwise the estimates of efficiency are likely to be biased. We also find that the failure to decompose efficiency into persistent and time-varying efficiency overestimated time-varying efficiency for banks of one ownership type. Furthermore, the failure to account for the determinants of production risks and inefficiencies results in the wrong estimates of scale economies, technical change and efficiency. Consequently, the use of misspecified models can undermine or overstate the effect of regulation for banks with different ownership types.

Our result from the four-component heteroscedastic model show that different banks responded differently to both deregulation and re-regulation. We identify losers and winners of regulation in terms of RTS, technical change and efficiency. The average RTS of foreign banks (private banks) declined (increased) over time with almost no change for state banks. The proportion of private banks with economies of scale increased from $44 \%$ to $86 \%$. The proportion of state banks operating at optimal scales increased from $77 \%$ during the deregulation era to $86 \%$ in the re-regulation period. Some of state banks had over-exploited economies of scale, and $11 \%$ of them started to experience diseconomies of scale. The technological progress of foreign banks during the early years of the re-regulation era is found to be the highest (but steadily declining) among banks of all ownership types. State banks, in contrast, are the only group where the change in regulation brought about technological 
improvement for all banks at a virtually constant rate. The change in regulation negatively affected the rate of change in the cost efficiency of all banks. We, however, find that it varies substantially across ownership type - only state banks maintained a steady efficiency level during the re-regulation era. If we consider overall efficiency, the combination of persistent and time-varying efficiencies, state banks managed to operate closer the their cost frontier, whereas foreign and private banks operated further away from their cost frontiers over time.

\section{References}

Altunbas, Y., Evans, L. and Molyneux, P.: 2001, Bank Ownership and Efficiency, Journal of Money, Credit and Banking 33(4), 926-954.

Berger, A., Klapper, L. and Turk-Ariss, R.: 2009, Bank Competition and Financial Stability, Journal of Financial Services Research 35(2), 99-118.

Berger, A. N., Hasan, I. and Zhou, M.: 2009, Bank Ownership and Efficiency in China: What Will Happen in the World' Largest Nation?, Journal of Banking 6 Finance 33(1), 113 130.

Bhattacharyya, A., Lovell, C. A. K. and Sahay, P.: 1997, The Impact of Liberalization on the Productive Efficiency of Indian Commercial Banks, European Journal of Operational Research 98(2), 332-345.

Boyd, J. H. and De Nicoló, G.: 2005, The Theory of Bank Risk Taking and Competition Revisited, The Journal of Finance 60(3), 1329-1343.

Burki, A. A. and Niazi, G. S. K.: 2010, Impact of Financial Reforms on Efficiency of StateOwned, Private and Foreign Banks in Pakistan, Applied Economics 42(24), 3147-3160.

Butler, J. S. and Moffitt, R.: 1982, A Computationally Efficient Quadrature Procedure for the One-Factor Multinomial Probit Model, Econometrica 50(3), 761-64.

Casu, B., Deng, B. and Ferrari, A.: 2016, Post-Crisis Regulatory Reforms and Bank Performance: Lessons From Asia, The European Journal of Finance pp. 1-28.

Casu, B., Ferrari, A. and Zhao, T.: 2013, Regulatory Reform and Productivity Change in Indian Banking, The Review of Economics and Statistics 95(3), 1066-1077.

Casu, B. and Girardone, C.: 2009, Testing the Relationship Between Competition and Efficiency in Banking: A Panel Data Analysis, Economics Letters 105(1), 134 - 137. 
Casu, B., Girardone, C. and Molyneux, P.: 2004, Productivity Change in European Banking: A Comparison of Parametric and Non-Parametric Approaches, Journal of Banking $\&$ Finance 28(10), 2521-2540.

Chen, X., Skully, M. and Brown, K.: 2005, Banking Efficiency in China: Application of DEA to Pre- and Post-Deregulation Eras: 1993-2000, China Economic Review 16(3), 229 - 245.

Coelli, T. J.: 1995, Estimators and Hypothesis Tests for a Stochastic Frontier Function: A Monte Carlo Analysis, Journal of Productivity Analysis 6(3), 247-268.

Colombi, R., Kumbhakar, S. C., Martini, G. and Vittadini, G.: 2014, Closed-Skew Normality in Stochastic Frontiers With Individual Effects and Long/Short-Run Efficiency, Journal of Productivity Analysis 42(2), 123-136.

Das, A. and Ghosh, S.: 2006, Financial Deregulation and Efficiency: An Empirical Analysis of Indian Banks During the Post Reform Period, Review of Financial Economics $\mathbf{1 5}(3), 193-221$.

Das, A. and Kumbhakar, S. C.: 2012, Productivity and Efficiency Dynamics in Indian Banking: An Input Distance Function Approach Incorporating Quality of Inputs and Outputs, Journal of Applied Econometrics 27(2), 205-234.

Doumpos, M., Gaganis, C. and Pasiouras, F.: 2015, Central Bank Independence, Financial Supervision Structure and Bank Soundness: An Empirical Analysis Around the Crisis, Journal of Banking \& Finance 61, Supplement 1, S69 - S83.

Evanoff, D. D. and Ors, E.: 2008, The Competitive Dynamics of Geographic Deregulation in Banking: Implications for Productive Efficiency, Journal of Money, Credit and Banking 40(5), 897-928.

Filippini, M. and Greene, W. H.: 2016, Persistent and Transient Productive Inefficiency: A Maximum Simulated Likelihood Approach, Journal of Productivity Analysis 45(2), 187196.

Fiordelisi, F., Marques-Ibanez, D. and Molyneux, P.: 2011, Efficiency and Risk in European Banking, Journal of Banking \& Finance 35(5), 1315-1326.

Fu, X. M. and Heffernan, S.: 2009, The Effects of Reform on China's Bank Structure and Performance, Journal of Banking $\&$ Finance 33(1), 39 - 52. 
Greene, H. W.: 2005, Reconsidering Heterogeneity in Panel Data Estimators of the Stochastic Frontier Model, Journal of Econometrics 126(2), 269-303.

Hao, J., Hunter, W. C. and Yang, W. K.: 2001, Deregulation and Efficiency: The Case of Private Korean Banks, Journal of Economics and Business 53(2-3), 237-254.

Hicks, J. R.: 1935, Annual Survey of Economic Theory: The Theory of Monopoly, Econometrica 3(1), 1-20.

Isik, I. and Hassan, M. K.: 2002, Technical, Scale and Allocative Efficiencies of Turkish Banking Industry, Journal of Banking \& Finance 26(4), 719-766.

Jaffry, S., Ghulam, Y. and Cox, J.: 2013, Trends in Efficiency in Response to Regulatory Reforms: The Case of Indian and Pakistani Commercial Banks, European Journal of Operational Research 226(1), 122-131.

Jondrow, J., Lovell, C. A. K., Materov, I. S. and Schmidt, P.: 1982, On the Estimation of Technical Inefficiency in the Stochastic Frontier Production Function Model, Journal of Econometrics 19(2-3), 233-238.

Just, R. E. and Pope, R. D.: 1978, Stochastic Specification of Production Functions and Economic Implications, Journal of Econometrics 7(1), 67-86.

Kumbhakar, S. C.: 1987, The Specification of Technical and Allocative Inefficiency in Stochastic Production and Profit Frontiers, Journal of Econometrics 34(3), 335-348.

Kumbhakar, S. C.: 1991, The Measurement and Decomposition of Cost-Inefficiency: the Translog Cost System, Oxford Economic Papers 43(4), 667-683.

Kumbhakar, S. C. and Heshmati, A.: 1995, Efficiency Measurement in Swedish Dairy Farms: An Application of Rotating Panel Data, American Journal of Agricultural Economics $77(3), 660-674$.

Kumbhakar, S. C. and Hjalmarsson, L.: 1993, Technical Efficiency and Technical Progress in Swedish Dairy Farms, in H. O. Fried, C. A. K. Lovell and S. S. Schmidt (eds), The Measurement of Productive Efficiency. Techniques and Applications, Oxford University Press, Oxford, pp. 256-270.

Kumbhakar, S. C. and Hjalmarsson, L.: 1995, Labour-Use Efficiency in Swedish Social Insurance Offices, Journal of Applied Econometrics 10(1), 33-47. 
Kumbhakar, S. C. and Lai, H.-p.: 2016, Maximum Likelihood Estimation of the Revenue Function System With Output-Specific Technical Efficiency, Economics Letters 138, 4245.

Kumbhakar, S. C., Lien, G. and Hardaker, J. B.: 2014, Technical Efficiency in Competing Panel Data Models: A Study of Norwegian Grain Farming, Journal of Productivity Analysis 41(2), 321-337.

Kumbhakar, S. C. and Sarkar, S.: 2003, Deregulation, Ownership, and Productivity Growth in the Banking Industry: Evidence from India, Journal of Money, Credit and Banking 35(3), 403-24.

Kumbhakar, S. C. and Sarkar, S.: 2005, Deregulation, Ownership and Efficiency Change in Indian Banking: An Application of Stochastic Frontier Analysis, in R. Ghosh and C. Neogi (eds), Theory and Application of Productivity and Efficiency, Econometric and DEA Approach, Macmillan, India, pp. 125-156.

Kumbhakar, S. C., Wang, H.-J. and Horncastle, A. P.: 2015, A Practitioner's Guide to Stochastic Frontier Analysis Using Stata, Cambridge University Press.

Leightner, J. E. and Lovell, C. A. K.: 1998, The Impact of Financial Liberalization on the Performance of Thai Banks, Journal of Economics and Business 50(2), 115-131.

Malikov, E., Restrepo-Tobon, D. A. and Kumbhakar, S. C.: 2014, Are All U.S. Credit Unions Alike? A Generalized Model of Heterogeneous Technologies with Endogenous Switching and Correlated Effects, MPRA Paper 55994, University Library of Munich, Germany.

McKillop, D. G., Glass, J. C. and Morikawa, Y.: 2004, The Composite Cost Function and Efficiency in Giant Japanese Banks, Journal of Banking \& Finance 20(10), 1651-71.

Okuda, H., Hashimoto, H. and Murakami, M.: 2002, Production Technology of Malaysian Commercial Banks: The Estimation of Stochastic Cost Functions Adjusted to The NonPerforming Loans, Discussion Papers 2002-04, Graduate School of Economics, Hitotsubashi University.

Okuda, H. and Mieno, F.: 1999, What Happened to Thai Commercial Banks in the PreAsian Crisis Period: Microeconomic Analysis of Thai Banking Industry, Hitotsubashi Journal of Economics 40(2), 97-121. 
di Patti, E. B. and Hardy, D. C.: 2005, Financial Sector Liberalization, Bank Privatization, and Efficiency: Evidence From Pakistan, Journal of Banking E Finance 29(8-9), 23812406.

Ray, S. C. and Das, A.: 2010, Distribution of Cost and Profit Efficiency: Evidence From Indian Banking, European Journal of Operational Research 201(1), 297-307.

Restrepo-Tobón, D., Kumbhakar, S. C. and Sun, K.: 2015, Obelix vs. Asterix: Size of US Commercial Banks and Its Regulatory Challenge, Journal of Regulatory Economics 48(2), 125-168.

Sealey, Calvin W, J. and Lindley, J. T.: 1977, Inputs, Outputs, and a Theory of Production and Cost at Depository Financial Institutions, Journal of Finance 32(4), 1251-66.

Triebs, T. P., Saal, D. S., Arocena, P. and Kumbhakar, S. C.: 2016, Estimating Economies of Scale and Scope With Flexible Technology, Journal of Productivity Analysis 45(2), 173186.

Tsionas, E. G. and Kumbhakar, S. C.: 2014, Firm Heterogeneity, Persistent and Transient Technical Inefficiency: A Generalized True Random-Effects Model, Journal of Applied Econometrics 29(1), 110-132.

Williams, J. and Intarachote, T.: 2002, Financial Liberalisation and Profit Efficiency in the Thai Banking System, 1990-1997: The Case of Domestic and Foreign Banks, Working paper, University of Wales, Bangor.

Williams, J. and Nguyen, N.: 2005, Financial Liberalisation, Crisis, and Restructuring: A Comparative Study of Bank Performance and Bank Governance in South East Asia, Journal of Banking \& Finance 29(8-9), 2119-2154.

\section{Appendix A Parameter estimates}




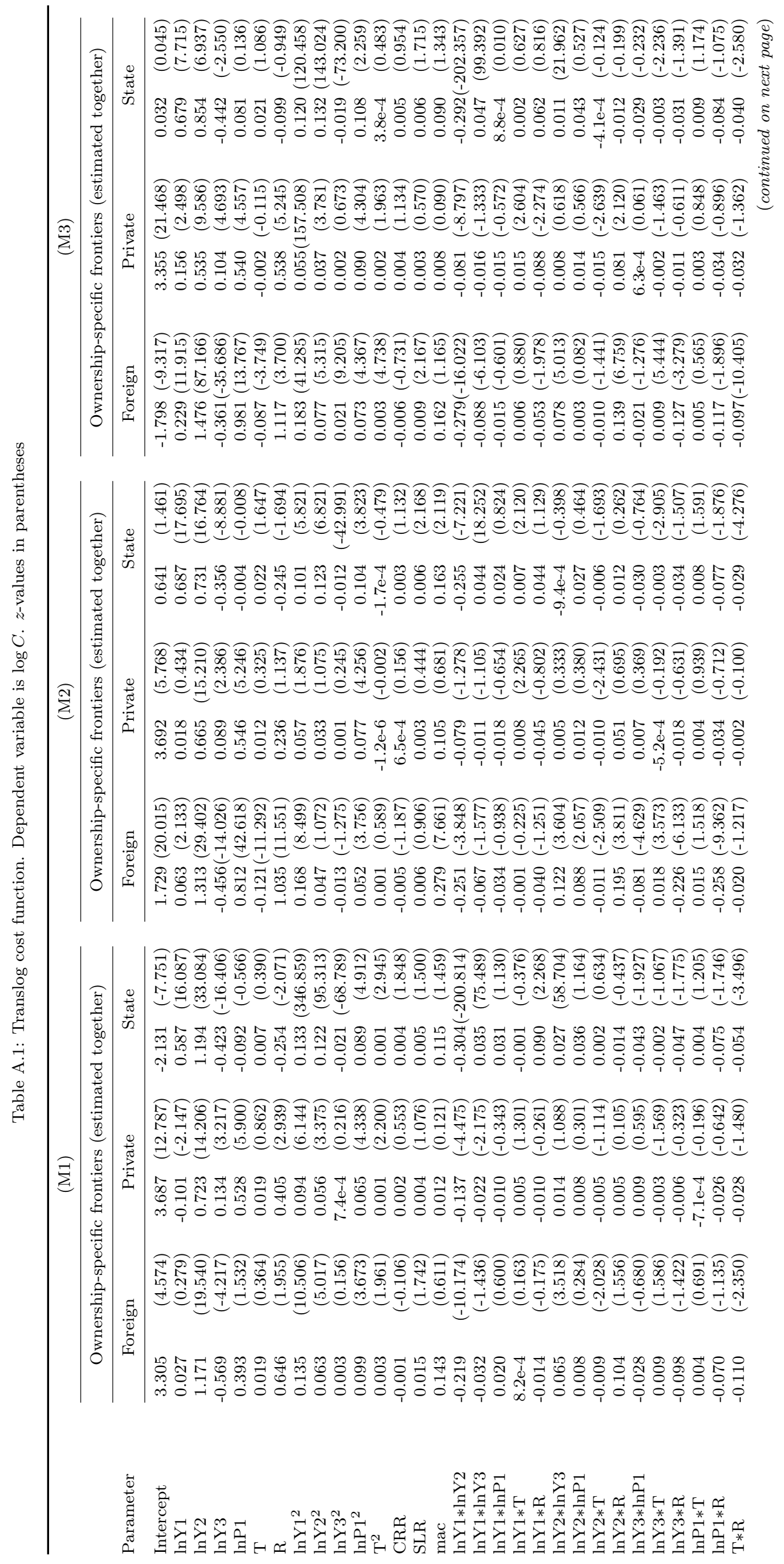




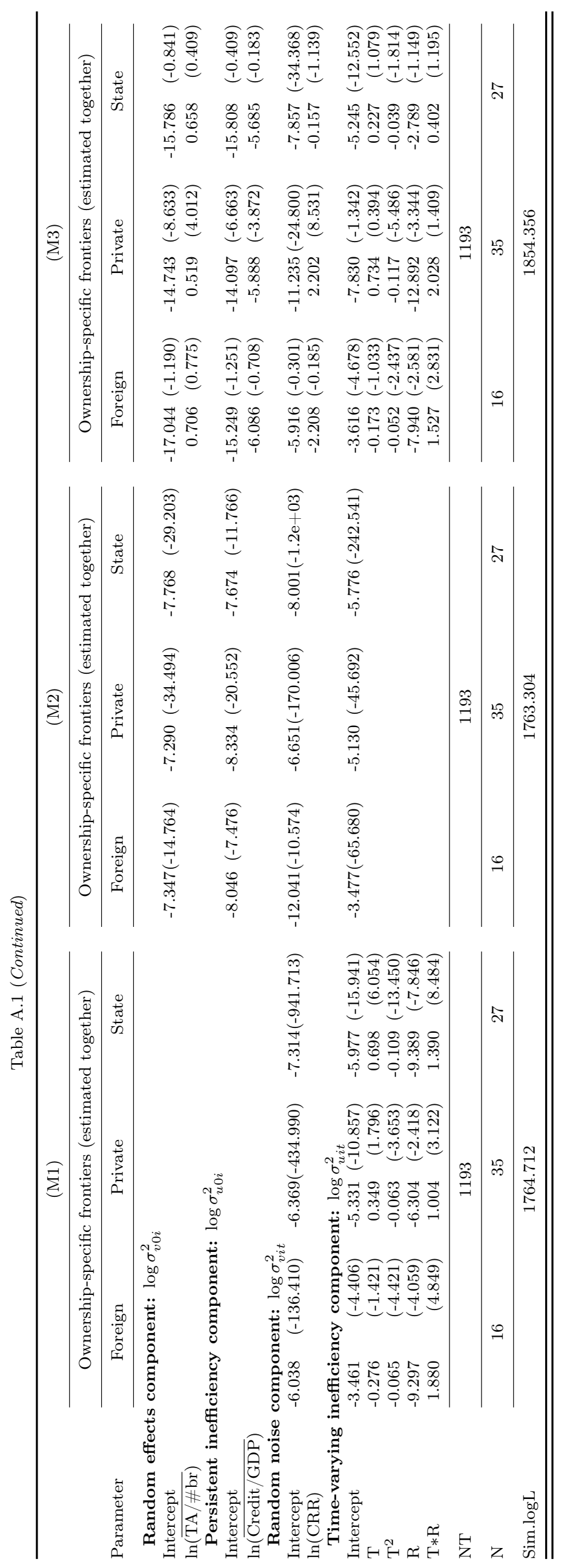

